Linköping University Medical Dissertations

No. 1563

\title{
TRIAGE \\ Management of the trauma patient
}

\author{
Maria Lampi
}

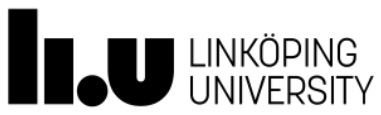

Department of Clinical and Experimental Medicine,

Center for Teaching and Research in Disaster Medicine and Traumatology

Linköping University Medical Faculty

SE-581 83 Linköping, Sweden

Linköping 2017 
(C) Maria Lampi, 2017

All rights reserved.

Artwork on cover created by Danne Linghammar.

Published articles have been reprinted with the permission of the copyright holder.

ISSN 0345-0082

ISBN 978-91-7685-574-4

Printed in Sweden by LiU-Tryck AB, Linköping, Sweden, 2016. 
"Om man lyfter blicken så ser man inga gränser" - Japanskt ordspråk 


\section{Supervisor}

Professor Tore Vikström, MD, PhD

Department of Clinical and Experimental Medicine

Linköping University, Sweden

\section{Co-supervisor}

Carl-Oscar Jonson, $\mathrm{PhD}$

Department of Clinical and Experimental Medicine

Linköping University, Sweden

\section{Faculty opponent}

Professor Ives Hubloue, MD, PhD

Department of Emergency Medicine

Disaster Medicine

Vrije Universiteit, Belgium 


\begin{abstract}
Triage, derived from the French word for sorting, aims to assess and prioritize injured patients, regardless of whether the injuries are sustained from everyday road traffic accident with few injured or a mass casualty incident. Triage seeks to provide the greatest benefit to the largest number of casualties in order to minimize morbidity and mortality. Triage in a pre-hospital setting entails management and sorting of patients according to an assessment of medical need, prioritization, and evacuation. In-hospital triage aims to rapidly identify the most injured and ensure timely and appropriate treatment according to the patient's clinical urgency. A number of different systems for performing triage have been established and implemented globally. The methodology is recognized and utilized but there is still a need for an evidence-based strategy to optimize training and the efficacy of the different systems.
\end{abstract}

The main aim of this thesis was to determine triage performance among prehospital personnel and investigate the potential advantage of a triage system for trauma patients. The papers included in this thesis evaluated the triage skills of physicians, pre-hospital personnel, and rescue services personnel by testing their performance before and after an educational intervention. The last paper evaluated potential benefits of using a triage system for trauma patients admitted to the emergency department at MOI Teaching and Referral Hospital in Eldoret, Kenya.

The results presented in this thesis illustrate that triage skills are lacking among physicians. Experienced pre-hospital personnel are more skilled in performing triage than physicians. The triage skills of the rescue services personnel improved significantly after the educational intervention. Moreover, the potential benefit to trauma patients of implementing an in-hospital triage system in a resource-poor environment was shown. In conclusion, health care personnel, especially physicians without experience but highly involved in trauma patient management, seem to be in need of triage training. How to train, how to implement, and how to evaluate triage skills must be considered in order to develop effective training. 


\section{POPULÄRVETENSKAPLIG SAMMANFATTNING}

Ordet triage kommer från franskans "sortera" och är ett av det första stegen i omhändertagandet av skadade när det råder resursbrist. Från 1800-talets blodiga slagfält, till dagens skadeplats och akutmottagningar har sättet att triagera patienter utvecklats. Men då, som nu, är grundtanken den samma, att sortera och prioritera de skadade utifrån tillgängliga resurser och patienternas vårdbehov. Följaktligen har begreppet kommit att bli centralt inom ämnet katastrofmedicin. Att avlida till följd av skador i samband med allvarliga händelser men också skador i till exempel vardagstrafiken är ett globalt hälsoproblem. Tiden från olycka till sjukhusbehandling är en viktig och ofta avgörande överlevnadsfaktor för en patient. I det här sammanhanget talas det om "den gyllene timmen", som påvisar vikten av att få adekvat behandling direkt efter olyckstillfället.

Arbetssättet att sortera och prioritera patienter är etablerat både på skadeplats och inne på sjukhus, men utförs med skiftande metoder nationellt och internationellt. Detta har medfört svårigheter att på ett vetenskapligt sätt kunna jämföra och utvärdera vilket system som genererar bäst resultat för patienterna. Utvärdering av triagesystem genomförs till stor del i simuleringsmiljö. Försök att utvärdera triagesystem har gjorts i samband med allvarliga händelser, men bristen på dokumentation leder till svårigheter att på ett vetenskapligt sätt kunna påvisa önskad effekt. För att kunna använda ett triagesystem krävs utbildning och återkommande övning.

Denna doktorsavhandling söker klargöra effekten av triagesystem och utvärdera förmågan hos läkare, prehospital personal och räddningstjänst att sortera och prioritera många svårt skadade före och efter olika triageutbildningar. Tre av de fyra i avhandlingen ingående studierna fokuserar på sortering och prioritering på skadeplats, och är genomförda i Sverige. Den fjärde studien är genomförd i Kenya, där fokus är sortering av skadade på en akutmottagning där de dagliga behoven vida överstiger de befintliga sjukvårdsresurserna.

Studierna visar att bättre utbildningar i triage behövs, speciellt hos den personal som har bristande vana att sortera och prioritera skadade patienter i samband med en stor skadehändelse. Vidare demonstreras att skadade patienter på en akutmottagning i Kenya skulle få behandling av läkare betydligt snabbare om ett etablerat triagesystem implementeras.

Sammanfattningsvis belyser denna avhandling vikten av att och hur triageträning genomförs, implementeras och utvärderas. 


\section{LIST OF ABBREVIATIONS}

$\begin{array}{ll}\text { AIS } & \text { Abbreviated Injury Scale } \\ \text { ATLS } & \text { Advanced Trauma Life Support } \\ \text { ATS } & \text { Australian Triage Scale } \\ \text { CATS } & \text { Canadian Triage and Acute Scale } \\ \text { DO } & \text { duty officer } \\ \text { ESI } & \text { Emergency Severity Index } \\ \text { ETS } & \text { Emergo Train System } \\ \text { GCS } & \text { Glasgow Coma Scale } \\ \text { ICD } & \text { International Classification of Diseases } \\ \text { ICISS } & \text { ICD-based Classification Injury Severity Score } \\ \text { ISS } & \text { Injury Severity Score } \\ \text { KTS } & \text { Kampala Trauma Score } \\ \text { MCI } & \text { mass casualty incident } \\ \text { METTS } & \text { Medical and Emergency Triage and Treatment System } \\ \text { MSB } & \text { Myndigheten för Samhällsskydd och Beredskap } \\ & \text { (Swedish Civil Contingencies Agency) } \\ \text { MTS } & \text { Manchester Triage System } \\ \text { NISS } & \text { New Injury Severity Score } \\ \text { PHTLS } & \text { Pre-Hospital Trauma Life Support } \\ \text { RETTS } & \text { Rapid Emergency Triage and Treatment Score } \\ \text { RTA } & \text { road traffic accident } \\ \text { RTS } & \text { Revised Trauma Score } \\ \text { SALT } & \text { Sort, Assess, Lifesaving measures, Treat/Transport } \\ \text { SRR } & \text { survival risk ratio } \\ \text { TRART } & \text { Simple Triage and Rapid Treatment } \\ \text { WHO } & \text { Trauma and Injury Severity Score } \\ \text { World Health Organization } \\ \text { TRS }\end{array}$





\section{LIST OF PAPERS}

This thesis is based on the following papers, which will be referred to in the text by their roman numerals.

I. Triage performance of Swedish physicians using the ATLS algorithm in a mass casualty incident: a prospective cross-sectional study

Lampi M, Vikström T, Jonson C-O.

Scandinavian Journal of Trauma, Resuscitation and Emergency Medicine 2013;21:90

II. Pre-hospital triage performance after standardized trauma courses

Lampi M, Junker J, Berggren P, Jonson C-O, Vikström T.

Scandinavian Journal of Trauma, Resuscitation and Emergency Medicine

Submitted

III. Improved and sustained triage skills in firemen after a short training intervention

Nilsson A, Åslund K, Lampi M, Nilsson H, Jonson C-O.

Scandinavian Journal of Trauma, Resuscitation and Emergency Medicine 2015;23:81

IV. Potential benefits of triage for the trauma patient in a Kenyan Emergency Department

Lampi M, Junker J, Tabu J, Berggren P, Jonson C-O, PhD, Vikström T.

Prehospital and Disaster Medicine

Submitted 


\section{TABLE OF CONTENTS}

INTRODUCTION 1

Triage

Under and over triage

Anatomic and physiologic triage ............................................ 3

Pre-hospital triage

Triage Sieve/Triage Sort ..................................................... 4

Simple Triage and Rapid Transport

Sort, Assess, Lifesaving intervention, and Treatment/transport .....6

In-hospital triage

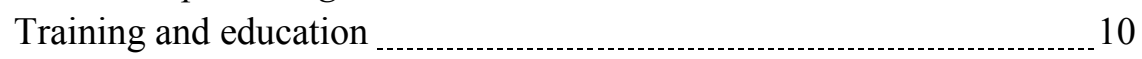

Teaching models and environments _...................................... 12

ATLS/PHTLS 13

Trauma

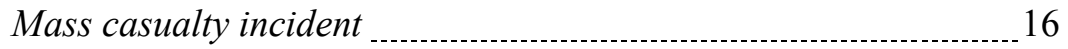

Swedish MCI organization

Trauma care and triage in low- and middle-income countries ......18

Scientific approach $\quad 20$

STUDY OBJECTIVES

MATERIAL AND METHODS

Papers I and II

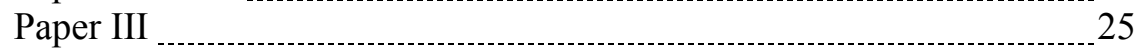

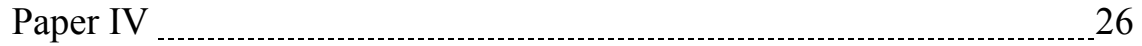

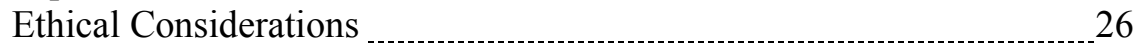

RESULTS

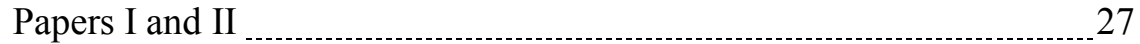

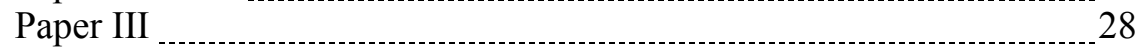

Paper IV $\ldots \ldots \ldots \ldots$

DISCUSSION 31

For the Future

ACKNOWLEDGEMENTS

REFERENCES

PAPER I _............................................. 49

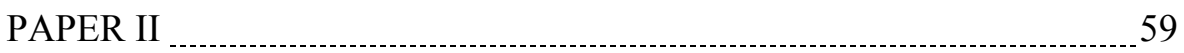

PAPER III $\quad 73$

PAPER IV 


\section{INTRODUCTION}

It has been said that triage in a disaster situation cannot be "taught it, must be lived". In some sense, this is probably true. Triage is a complex process requiring medical experience and understanding of the dynamic changes in the medical condition of the casualty. The nature of the incident, number of affected patients, transportation needs, distances, hospital capabilities and resource availabilities are all factors to be considered in triage management.

We as medical personnel are required to learn and improve our triage skills. This knowledge comes not only from those who have experienced real incidents and performed triage but also from the scientific investigations performed by experienced researchers in their attempts to move the triage research area forward. This will enable us to "do the greatest good for the greatest number of patients".

\section{Triage}

The definition of triage used in the context of this thesis is management and sorting of patients according to an assessment of medical need, prioritization, and evacuation, by the use of a sorting system or algorithm. In a disaster, triage seeks to provide the greatest benefit to the largest number of casualties in order to minimize morbidity and mortality [1]. Triage has been described as one of the key factors in patient management in disaster situations [2,3]. Triage discussed within this thesis focuses on pre-hospital and in-hospital settings.

The word triage is derived from the French verb trier, which means "to sort". The first documented triage system leads us back to the 18th century and to military medicine. Baron Dominique-Jean Larrey, chief surgeon of Napoleon's Imperial Guard established a system to treat and evacuate the wounded soldiers during combat, instead of postponing care of the injured patients until the war was over [4]. Triage evolved, perhaps even in Napoleon's time, into a method for assigning priorities for treatment of the injured when resources were limited.

Prioritizing patients in a mass casualty incident (MCI) setting can be a demanding task for health care personnel $[5,6]$. The situation is often combined with limited resources, lack of information, and work under extreme pressure and severely injured patients. The decision-making process changes from field triage, which is a procedure based on guidelines to apply routine triage in the 
pre-hospital setting [7], to disaster triage. Field triage prioritizes casualties according to severity of injuries and the need for immediate lifesaving care, whereas disaster triage aims at doing "the greatest good for the greatest number" of casualties. Disaster triage may be demanding for medical providers from a moral and ethical perspective [3]. To be able to handle these situations, triage systems have been developed and implemented around the world. The goal of such systems, protocols and algorithms is to ensure the best possible opportunity for survival of all the victims involved [8]. The methodology and performance of triage has been recognized and utilized; however, there is still a need for an evidence-based strategy [8].

Studies have attempted to assess the validity and reliability of various triage systems [9-12]. Reliability refers to the degree to which repeated assessment of the same patient with a triage instrument will deliver the same acuity level. Validity refers to the degree with which the measured acuity level reflects the patient's true acuity at the time of triage [13]. Validity can be determined by measuring how well the triage system can predict the outcome of the patients (predict validity). Predicting validity is a method frequently used in triage studies [11]. Unfortunately, it may not be possible to measure the truth for patient acuity, as many factors have an impact on the care of the patient. "Surrogate" outcome markers have been used as criteria to assess validity [13]. The most important surrogate outcome measures include mortality, resource utilization and hospital length of stay [11].

\section{Under and over triage}

The accuracy of triage can be classified and evaluated using the terms under and over triage [14-16]. An under triaged patient has life-threatening injuries but is assessed as non-critical, which may lead to delayed medical interventions and/or evacuation to hospital [17]. This inaccurate triage decision may delay the patient's immediate care, especially when resources are limited or strained [18]. An over triaged patient, on the other hand, is triaged as severally injured, thus resulting in rapid evacuation to hospital. The American College of Surgeons Committee on Trauma stipulates a goal of $<5 \%$ under triage and $25-50 \%$ over triage [14]. Both under and over triage errors can generate risk for increased morbidity and/or mortality $[3,18]$. 


\section{Anatomic and physiologic triage}

Triage used in the pre-hospital setting is mainly based on anatomic or physiologic data, separately or in combination. Guidelines published in 2010 recommend that triage should be based on a combination of physiologic and anatomic parameters, along with the mechanism of injury, comorbidities, and demographics [19]. By only using anatomic triage decisions based on the patient's visible injuries, there is a risk of failing to identify severe injuries such as cavity hemorrhage $[7,20]$. On the other hand, a trauma patient may display normal physiologic parameters but have visible signs (i.e., soot in the nostrils after exposure to fire) and be at potential risk of developing later complications [7].

Triage systems based on physiologic parameters include factors such as respiratory rate, palpable radial pulse, capillary refill, and Glasgow Coma Scale (GCS), among others [21]. Some physiologic triage systems have been reviewed with regard to which physiologic variable has the strongest association with the severity of injury [22]. Registered physiologic parameters are inserted into an algorithm and generate a priority and color code. This has been shown to be advantageous for personnel with limited clinical experience and knowledge [23]. A disadvantage with this method is that the physiologic parameters are assessed at the time of triage, not taking into account the patient's dynamic condition.

Triage is and has to be a dynamic process, which means that the triage decision must be re-evaluated and adjusted with regard to the patient's condition and effects of interventions [24]. The triage decision can be subject to change, even when originally made by experienced medical personnel [25] and must be evaluated as the patient undergoes transport and treatment. Even though the triage system is structured, experienced personal make their decisions based on immediately available resources, which is experience and knowledge. Their personal judgment may even take precedence over the use of triage instruments and a combination of structured triage systems and judgment seems to be efficient [25]. "Gut-feeling" can also be a primary criteria that can be practiced and used as an informal triage methodology, together with a structured triage approach [26]. 


\section{Pre-hospital triage}

A large number of pre-hospital triage systems exists worldwide. The main differences between these systems rest in how patients are triaged to each level, as well as the number of levels used, the colors used to categorize, or classification to further stratify casualties [21]. However, triage systems have several structures in common. Most have a "walking filter" to identify and rapidly discriminate the most severely injured patients and evacuate them from the immediate hazard zone [21]. The use of color codes, generally red, yellow, green, and black, to identify severity levels are common in most triage systems. Tags, a practical device used for triage by ambulance personnel, are attached to each patient and follow this color code [27]. The following paragraphs describe some of the most commonly used pre-hospital triage systems.

\section{Triage Sieve/Triage Sort}

"Triage Sieve" and "Triage Sort" is a two-step triage model described and used in the Major Incident Medical Management and Support course (MIMMS) [28]. The methodology has been widely advocated in the United Kingdom, parts of Australia, and in several regions in Sweden [22]. The first step, Triage Sieve, is intended to be used at the incident site for primary sorting with a walking filter. This stage represent a very rapid form of triage, entirely conducted according to respiratory rate and capillary refill time or heart rate, in order to classify the patient into triage categories $[21,28]$. A scientific evaluation of Triage Sieve was conducted retrospectively after the London bombings [29]. In that study, Triage Sieve was compared with START and CareFlight Triage to demonstrate their relative efficiency. The systems performed identically in identifying the most severely injured. However, missing data compromised the attempt to evaluate the systems.

The second stage, Triage Sort, is based on a combination of anatomic and physiologic parameters. Triage Sort is based on the Revised Trauma Score (RTS) [30], an injury scoring system aimed at classifying trauma patients and assisting in clinical decision making for adults and pediatric trauma patients [31]. RTS assesses three parameters: neurologic evaluation by the GCS, hemodynamic evaluation by systolic blood pressure, and respiratory rate [30]. 


\section{Simple Triage and Rapid Transport}

Simple Triage and Rapid Transport (START) was developed in the 1980s as one of the first civilian triage systems used in MCIs (figure 1). The START model has been described as one of the most commonly used triage systems for handling MCIs in the United States, and is also used in Canada, Saudi-Arabia, parts of Australia and Israel [21]. The system uses a qualitative, fixed-priority method [32]. The triage categorization is based on whether the patient can walk, respiratory rate, perfusion, and mental status. It is designed so that the provider can complete an assessment within 60 seconds [21], based on strict medical criteria, and thereby identify the patients' medical needs. Thereafter, the provider follows a fixed-priority policy in terms of one of four triage classes ending in a color code [32]. START is designed for adults. JumpSTART is based on START and is designed to account for the unique physiology of children [33]. Despite its widespread use, START has not been validated. The system has been studied in correlation with clinical outcome as a post-event review of an actual disaster [34-36].

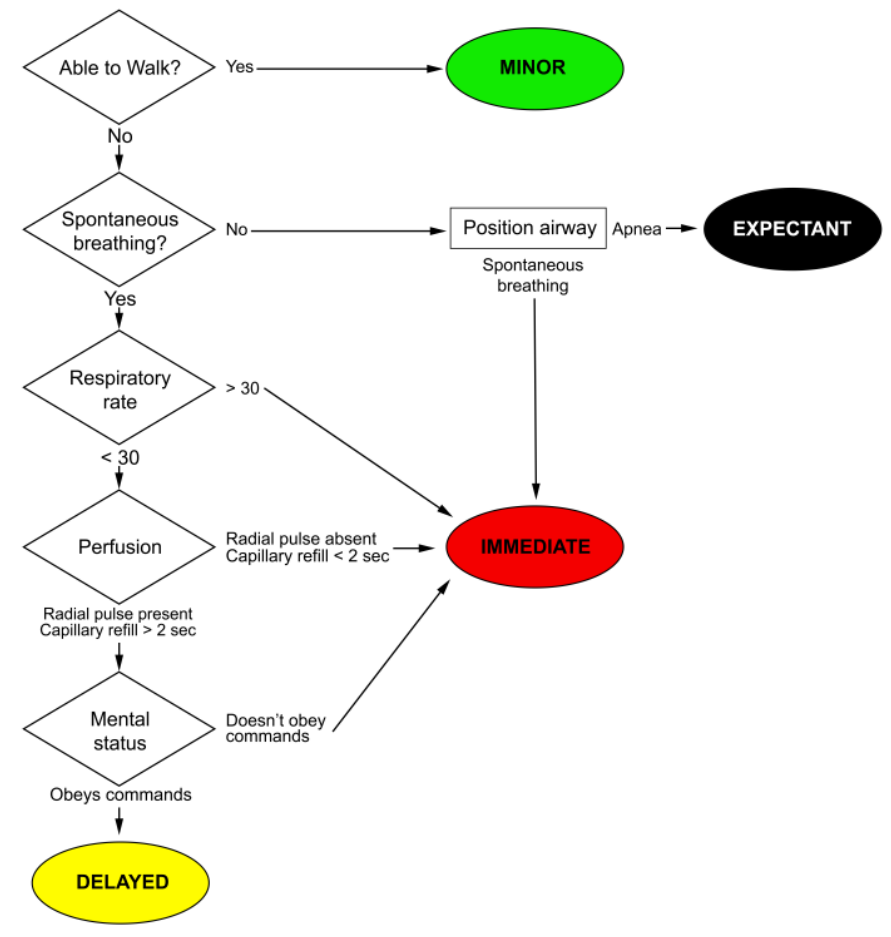

Figure 1. START algorithm (adapted from START Triage [37]). 


\section{Sort, Assess, Lifesaving intervention, and Treatment/transport}

The Sort, Assess, Lifesaving intervention, and Treatment/transport (SALT) system combines sorting and basic lifesaving interventions and is designed for both adult and pediatric patients [33]; it incorporates operational considerations in a qualitative way (figure 2). The model breaks triage down into two steps. The first step divides patients into three categories: walking, cannot walk but can wave/purposefully respond, and still/unresponsive. The next step, assessment and lifesaving treatment includes controlling hemorrhage, opening airway/rescue breaths, auto injector antidotes, and chest compressions. Thereafter, the provider gives the injured a color code based on the physical response of the assessment [37]. Experts have developed the SALT model by combining structures of the existing triage systems and best available evidence. It has been suggested as a US national guideline for mass casualty triage [38]. The SALT principles are also the basis for the national guidelines for mass casualty triage in Norway [39].
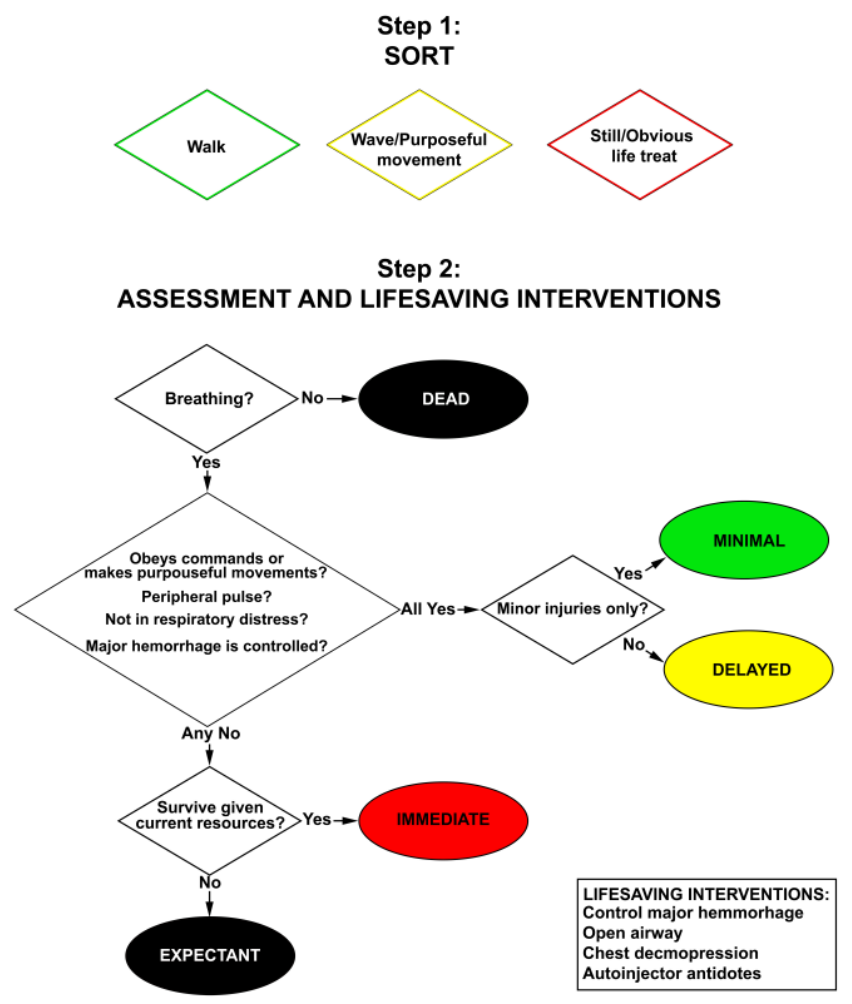

Figure 2. The SALT algorithm (adapted from [38]). 
Neither SALT nor START takes the number of resources or casualties into account. Today, there is evidence indicating that SALT and START can lead to over triage $[35,40]$, and neither are sensitive or specific enough to predict clinical outcome [37].

There is extensive research published on triage in an MCI scenario, yet few studies address the validation of triage tools [41-44]. The lack of standardized mass casualty triage algorithms has the potential to cause significant confusion. The absence of guidelines has resulted in variability in the triage process, as well as in the tags and the nomenclature used. Still, no international guideline for mass casualty triage exists. Moreover, few countries have national standards for triage assessment.

\section{In-hospital triage}

Triage is an essential function in the emergency department (ED), where many patients may present simultaneously. The aim of an in-hospital triage system is to rapidly identify patients with life-threatening conditions, ensure treatment in order of clinical urgency, and that treatment is appropriate and timely $[9,45,46]$. Worldwide, there are four well-recognized triage systems in use in the ED, all with an established five-level triage algorithm. This five-level algorithm has been shown to be superior to three-level systems with regard to validity and reliability [11,47]: the Australian Triage Scale (ATS), the Canadian Triage and Acute Scale (CATS), the Manchester Triage System (MTS) and the American Emergency Severity Index (ESI) [9,11,48,49]. In Sweden, Rapid Emergency Triage and Treatment System (RETTS) is the most frequently implemented system (table 1). During an initial period, RETTS changed its name to the Medical and Emergency Triage and Treatment System (METTS) [50], and thereafter changed the name again to RETTS. 
Table 1. Triage algorithm for vital signs according to RETTS [50].

\begin{tabular}{|c|c|c|c|c|c|c|}
\hline Step & Method & Red & Orange & Yellow & Green & Blue \\
\hline A & Inspection & $\begin{array}{l}\text { Airway } \\
\text { compromised }\end{array}$ & Not used & Not used & Not used & $\begin{array}{l}\text { Not in need } \\
\text { of triage }\end{array}$ \\
\hline B & $\begin{array}{l}\text { RR and } \\
\text { POx }\end{array}$ & $\begin{array}{l}\mathrm{RR}>30 \text { or }<8 \\
\mathrm{POx}<90 \% \\
\text { w/ oxygen }\end{array}$ & $\begin{array}{l}\text { RR }>25 \\
\text { POx }<90 \% \\
\text { w/o oxygen }\end{array}$ & $\begin{array}{l}\mathrm{RR}<25 \\
\text { POx } 91-95 \% \\
\text { w/o oxygen }\end{array}$ & $\begin{array}{l}\text { RR 9-25 } \\
\text { POx> } 95 \% \\
\text { w/o oxygen }\end{array}$ & \\
\hline C & $\begin{array}{l}\mathrm{HR} \text { and } \\
\text { SBP }\end{array}$ & $\begin{array}{l}\mathrm{HR}>130 \\
\mathrm{SBP}<90\end{array}$ & $\begin{array}{l}\mathrm{HR}>120 \\
\text { or }<40\end{array}$ & $\begin{array}{l}\mathrm{HR}>110 \\
\text { or }<50\end{array}$ & HR 51-109 & \\
\hline D & RLS & $\begin{array}{l}>3 \text { or } \\
\text { ongoing } \\
\text { seizure }\end{array}$ & $2-3$ & Confusion & Alert & \\
\hline $\mathbf{E}$ & $\begin{array}{l}\text { Body } \\
\text { temperature }\end{array}$ & Not used & $>41$ or $<35$ & $38.5-41$ & $35.1-38.4$ & \\
\hline
\end{tabular}

Since 2010, most EDs in Sweden use RETTS, which is a process-oriented triage scale based on physiologic parameters [46]. RETTS has two main assessment variables: vital signs and chief complaints, which describe the symptoms and incident that caused the patient to seek care. These two variables are evaluated and result in a color-coded 5-level scale. Each level of priority has a defined time limit, which dictates the maximum time to evaluation and treatment by a physician.

The process of triage described above seem to function well in developed countries, but have been described as unsuited and difficult to implement in developing countries [51]. In resource-poor settings, there is a need for a triage system that does not require extensive training, can handle a large number of severely injured patients, and is applicable in situations with medical staff shortages and limited resources [52]. The South African Triage Score (SATS) was developed in 2006 in South Africa and has been proposed for urban and rural hospitals in developing countries [53]. SATS uses a scoring system based on physiologic parameters, the Triage Early Warning Score (TEWS), and a list of identifiable clinical conditions (table 2). 
Table 2. SATS comprising TEWS and discriminator score [53].

\begin{tabular}{|c|c|c|c|c|c|c|c|}
\hline TEWS & 3 & 2 & 1 & $\mathbf{0}$ & 1 & 2 & 3 \\
\hline Mobility & & & & Walking & With help & $\begin{array}{l}\text { Stretcher/ } \\
\text { immobile }\end{array}$ & \\
\hline RR & & $<9$ & & $9-14$ & $15-20$ & $21-29$ & $\geq 30$ \\
\hline HR & & $\leq 40$ & $41-50$ & $51-100$ & 101-110 & $11-129$ & $\geq 130$ \\
\hline SBP & $\leq 70$ & $71-80$ & $81-100$ & 101-199 & & $\geq 200$ & \\
\hline Temperature & & $\begin{array}{l}\text { Cold or } \\
<35^{\circ} \mathrm{C}\end{array}$ & & $\begin{array}{l}35.0^{-} \\
38.4^{\circ} \mathrm{C}\end{array}$ & & $\begin{array}{l}\text { Hot or } \\
\geq 38.5^{\circ} \mathrm{C}\end{array}$ & \\
\hline AVPU & & Confused & & Alert & Voice & Pain & Unresponsive \\
\hline Trauma & & & & No & Yes & & \\
\hline
\end{tabular}

$R R=$ respiratory rate (breaths/min), $H R=$ heart rate (beats/min), SBP = systolic blood pressure, AVPU $=$ Alert Voice Pain Unresponsive.

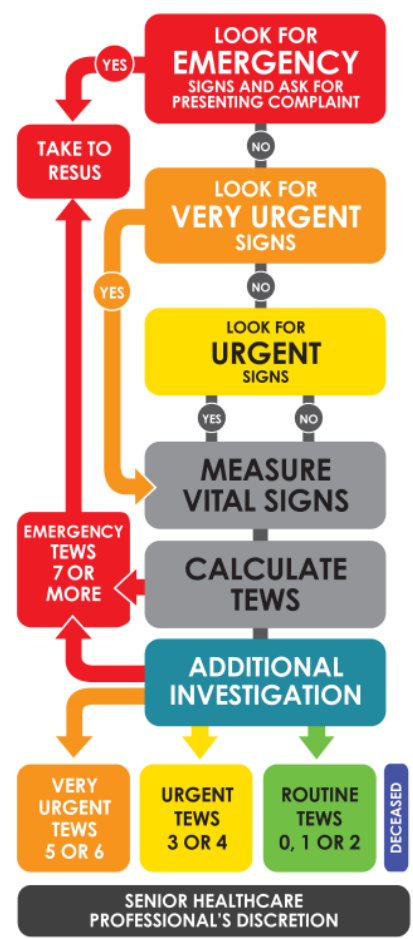

Like RETTS, SATS is designed to triage patients into five color-coded categories for medical assessment (figure 3, table 3) [54]. SATS has been successfully implemented in countries outside South Africa such as Pakistan and Somaliland [54,55]. The outcome of the implementation of SATS has been correlated with a reduction of mortality, shorter waiting times, and improvement of patient flow [55].

Figure 3. SATS algorithm. 
Table 3. Target time to treatment according to SATS categorization based on TEWS score [53].

\begin{tabular}{lccccc} 
& Red & Orange & Yellow & Green & Blue \\
\hline TEWS & 7 or more & $5-6$ & $3-4$ & $\leq 2$ & Dead \\
Target time to treat & Immediate & $<10 \mathrm{~min}$ & $<60 \mathrm{~min}$ & $<4 \mathrm{~h}$ & \\
\hline
\end{tabular}

\section{Training and education}

Adequate preparation and training is essential for successful management of patients during an MCI. The relatively rare incidence of such an event can be a demanding problem when designing a training system. Retaining knowledge over time is a significant challenge in response training, and requires repeated training sessions. Consequently, extensive training and education to prepare for an event with a low probability of occurring is difficult to justify. Moreover, the nature of an MCI makes proper follow-up and evaluation demanding, because all available resources are focused on treating patients. This leads to difficulties in evaluating the positive effects of the training. Another significant problem related to developing training for MCI management, is the design of exercises in which medical personnel have the opportunity to practice skills interdependently of each other and simulate a high work load and severe time pressure [56].

Triage has been identified as one of the areas in disaster medicine for which training is especially important $[1,57]$. Triage is rarely used in the daily management of injured patients, and in combination with the rare occurrence of MCIs, practice and exercise is essential $[3,58]$. Lessons learned from real incidents illustrate the need for triage training [59].

Research in disaster medicine indicates that no training in triage can entirely prepare health care personal for a real mass casualty event. However, familiarity with the process helps their efficiency and performance comfort [60]. Teaching and assessing abilities in performing mass casualty triage is inherently challenging due to the inability to accurately replicate a disaster or mass casualty incident environment in a comprehensive way. Therefore, mock drills are one principal form of applied mass casualty training with mock patients or dummies [61]. Moreover, exercises and simulations have been shown to be an effective way to assess different areas of disaster management to test and evaluate performance in, for example, decision making, triage, and patient management [62,63]. One simulation tool, Emergo Train System ${ }^{\circledR}$ (ETS) [64], was developed in Sweden 
[65] but is currently adapted for international use in several parts of the world [64]. The core of the ETS is the patient bank together with staff and resources involved in disaster management [66]. All victims belong to an injury category, and each victim has a defined medical need, which has to be assessed within a stipulated time. Otherwise the casualty is at risk of preventable complications or death. As an exercise evaluation, it is possible to measure patient outcome and relate that to the treatment and to other decisions taken by the participants. In concordance with ETS, an interactive teamwork concept for pre-hospital personnel has been developed, tailored for triage training, utilizing specific trauma cards (figures 3,4$)[64]$.
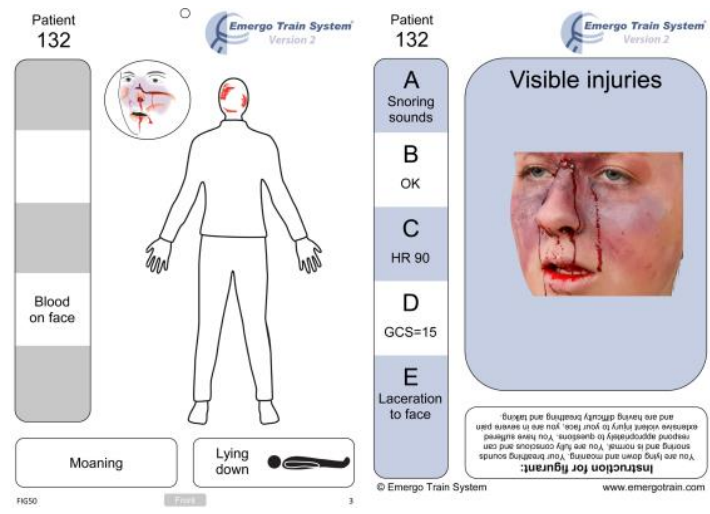

Figure 4. Front (left) and back (right) of EmergoTrain System Trauma card [64]. The front of the card contains the initial information given to the participants at first glance. The back of the card contains information obtained after primary assessment of the "patient".

Other interactive models such as table-top exercises and computerized simulation models are frequently used in MCI triage training [67-69].

Evaluation is part of an effective training system and indicates if the training objectives have been achieved and whether accomplishment of the objectives have resulted in enhanced performance [70]. Historically, training researchers have relied on an evaluation model, proposed by Kirkpatrick [71]. Kirkpatrick's framework has limitations but still remains as a base for evaluation of trainees $[72,73]$. Within this model, learning skills can be assessed by using multiplechoice tests [70]. Training evaluation with pre-tests and post-tests is a way to measure change and level of achievement [74]. 


\section{Teaching models and environments}

Adult learning diverges from how young children learn because adults are usually voluntary learners. Medical personnel come to training with experience, knowledge and skills, and the trainer needs to make the training relevant to the learners. Studies have shown that one way of learning is when the trainee can relate new material to what is already known and needs new knowledge to build up logically with clear objectives $[75,76]$.

Adult learning theory highlights the important role of learners as active participants in their learning process. Activation can facilitate "in action learning" by methods such as simulated emergency scenarios $[56,75]$.

In the mid-1980s, David Kolb proposed that adult learning is more effective when learners are more directly involved instead of receiving knowledge communicated by the teacher [77]. Kolb developed "the experiential learning cycle" in which there are four distinct stages of learning [78]. While the cycle can start at any stage, all stages are required to learn effectively:

- Concrete experience - active learning as opposed to passive. Learn about something by being directly involved with the material rather than learning about it.

- Reflective observation - refers to thinking critically about experience.

- Abstract conceptualization - linking the experience to the theory or concepts underlying it.

- Active experimentation - testing out one's learning in new situations.

Experiential learning theory defines learning as "the process whereby knowledge is created through the transformation of experience" [77] and has become to be known as "learning by doing" or "hands-on learning". This does not express its complexity. However, this type of learning is far beyond simple. It is a matter of being more engaged in one's learning cognitively, which is a deep level processing of knowledge/skills through experience, reflection, experimentation, and application [79].

It has been demonstrated that adults have different learning styles. Adults improve their learning if the material is reinforced with visual aids, and handson activities enhance some learners. When medical personnel are involved and in charge of their own training, they are more engaged, and improvement of 
their knowledge increases. It is important that the environment is non-competitive, which encourages the learners to share information with each other and thereby increasing the knowledge and making it more valuable $[76,80,81]$.

Adult learners need goal-oriented, relevant, practical experiences in order to get the most from teaching [82]. To learn as an adult, a didactic approach is relatively ineffective and physicians, like other adults, learns far better with experiential learning, for example, participatory training such as simulation, which provides greater realism than a didactic approach and enables the level of difficulty to be individualized with immediate feedback [83].

To summarize, education and training in triage and MCI management is a demanding challenge for teachers and learners alike, and needs further development with the goal of enhancing effective emergency preparedness and response [84]. Decisions on what to train, how to train and how to implement and evaluate training with evidence-based best practice is important to ensure training effectiveness [73].

\section{ATLS/PHTLS}

Several courses and education programs that include elements of triage training have been developed. The Advanced Trauma Life Support (ATLS) course was developed by the American College of Surgeons and is often a requirement for a resident degree in anesthesia, orthopedics, surgery and emergency medicine in northern Europe [85]. The course is highly recommended for all doctors who are involved in the management of trauma patients [86], and it has been accepted worldwide as a training concept for medical doctors $[87,88]$. The ATLS program is implemented in more than 60 countries worldwide and more than 1.5 million physicians have graduated and received the ATLS diploma. During the course, trauma triage principles are introduced by applying the mnemonic $\mathrm{ABCDE}$ in a group discussion according to the ATLS curriculum [89]. Physicians involved in initial patient treatment in a disaster situation could play a key role if they have been trained within the ATLS program [90,91].

Pre-hospital Trauma Life Support (PHTLS) was developed by the American College of Surgeons and is accepted worldwide; it provides the opportunity to standardize pre-hospital trauma management [92]. The PHTLS course contains no triage lecture, but the PHTLS manual includes a chapter on triage and initial stabilization.

The PHTLS and ATLS courses are designed to teach providers a standardized approach to trauma assessment, and the sequences combine the educational 
formats of lectures and practical lifesaving skills. Both concept courses emphasize that injury kills within certain time frames, and evaluation and interventions should follow the structured examination from A to $\mathrm{E}$. The mnemonic ABCDE prompts the specific order to be followed [7].

\section{Trauma}

Trauma is defined as an injury resulting from a physical force making contact with the body. This force can be blunt or penetrating. Blunt or non-penetrating trauma occurs mainly in motor vehicle accidents and falls, while penetrating trauma includes gunshot and stab wounds [89]. Thermal trauma is when the patient has been exposed to fire, electrical injuries, hypothermia, and frostbite. The severity of the injury is related to the force and duration of impact, the body part involved, and the injuring agent [92]. Pre-existing influences such as age, medications, and co-morbidity factors may also affect the degree of trauma [89]. In a physiologic sense, trauma is not a single insult; it is a combination of hemorrhage, tissue injury, pain, and fear. To understand the physiology of trauma, all these components have to be considered.

A systematic review published in 2016 summarizes trauma studies performed over 30 years, and identifies that brain injury, exsanguination, and a combination of brain injury and severe bleeding were the leading causes of death after trauma [93]. Bleeding has been shown to be the leading cause of preventable deaths among trauma patients [94]. In this context, identification and timely management of hemorrhage to minimize the time between injury and intervention is essential [95]. A classification of estimated blood loss based on clinical signs is used in the ATLS curriculum [89]. This classification can be used as a practical guideline. Clinical symptoms such as heart rate above $100 \mathrm{bpm}$, tachypnea, and decreased pulse pressure occur when a $70-\mathrm{kg}$ man is subjected to a blood loss of $750-1500 \mathrm{ml}$ ( $15 \%$ to $30 \%$ of total blood volume). This is defined as class II hemorrhage. A class III hemorrhage involves the loss of approximately $1500-2000 \mathrm{ml}$ of blood, which leads to marked tachycardia and tachypnea, significant changes in mental status, and a measurable decrease in systolic pressure.

The survival time, which is the time from injury until death, has a "trimodal distribution" (figure 5). 


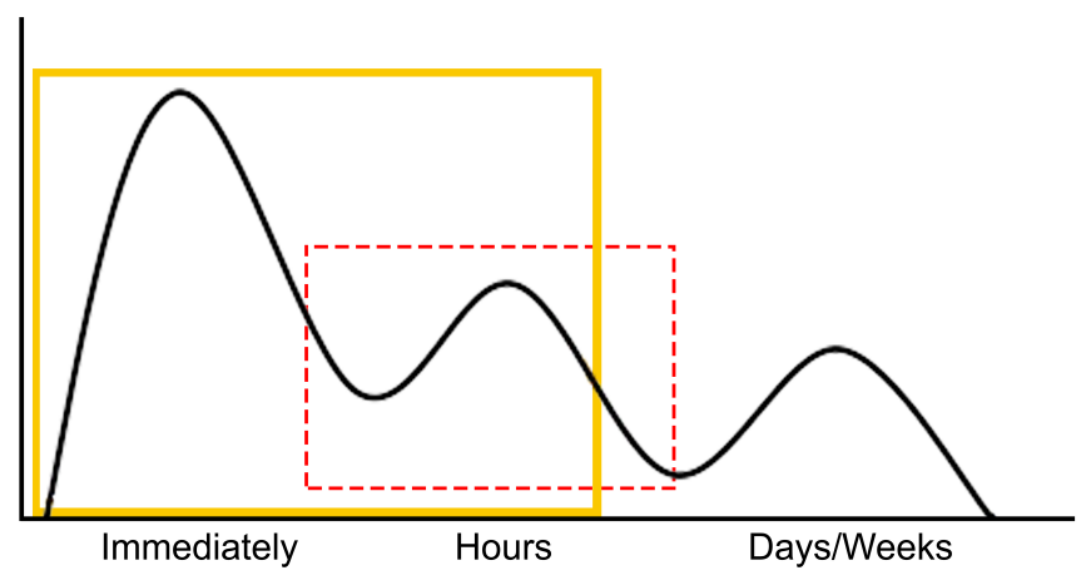

Figure 5. Schematic visualization of the concept of trimodal mortality. The three distinct peaks represent immediate, early, and late deaths occurring after traumatic injury. The golden rectangle illustrates "the golden hour". The red dashed rectangle illustrates the main target of possible improvement by using a triage system.

This distribution shows an initial peak of "immediate deaths" followed by a second peak of "early deaths" in the first hours, and finally a third peak of "late deaths" days or weeks later. This classification was first described by Trunkey [96], and has been a focus of debate because trauma deaths are not always demonstrated in these time frames $[97,98]$. However, the concept of trimodal distribution is still used by the American College of Surgeons to teach physicians around the world about the golden hour of care, the different causes of early and late mortality, and different potential interventions [89,98]. The second peak in the trimodal distribution, early deaths, is defined as deaths within hours of arrival at the hospital. Deaths that occur during this period usually result from brain injury, hemo-/pneumothorax, lacerations on the spleen and liver, pelvic fractures and/or multiple other injuries associated with significant blood loss [89].

The global epidemiologic characteristics, studying the mechanism of injury due to an MCI with mortality as an outcome, are related to road traffic accidents $[99,100]$. Brain injuries and fractures are also common in other incident types, for example, earthquakes [101].

Despite the type of incident, a single trauma patient or an MCI, the patient has the same physiology due to the mechanism of injury. To identify hemorrhagic shock in a trauma patient only assessing vital signs is demanding, and the 
associated difficulties have been discussed [95]. When an MCI occurs and several patients are traumatized with similar conditions, in combination with a general lack of resources, the situation becomes even more demanding. To be able to make a difference to the patient outcome, the triage system that we use must support and guide us to sort and prioritize patients according to injury severity. By utilizing knowledge of the physiologic response of the casualty, in combination with understanding the trimodal mortality model described above, the second peak has been identified as the main target to improve management of the greatest number of patients (figure 5) [97].

\section{Mass casualty incident}

A bus crash in a small rural community with 20 casualties with minor injuries has occurred. Is this an MCI? Or, is a bus crash with five severe injuries an MCI? The first example might not necessarily require a full major incident response, while five casualties with critical injures may. Definitions of MCIs vary, and attempts to define a specific number of casualties for an incident to be considered an MCI have been made. The World Health Organization (WHO) defines an MCI as "an event, which generates more patients at one time than locally available resources can manage using routine procedures. It requires exceptional emergency arrangements and additional or extraordinariness assistance" [102]. This definition is based on available resources, number of casualties, and the severity of injuries. Sometimes the word "disaster" is used as a synonym for MCI [1,57]. A disaster, classified from a medical point of view, is disproportion resulting from an increased demand for medical response and the actual medical resources available in order to manage the causalities [1]. In the Swedish context, the term major incident is used and defined "where available resources are insufficient for the immediate need of medical care" and the situation require a specific health care organization [24]. In the United Kingdom, an MCI is defined as "an emergency that requires the implementation of special arrangements by one or more of the emergency services and will generally include the involvement, either directly or indirectly, of large numbers of people" $[103,104]$. These definitions emphasize the initial balance between immediate medical response and access to resources, regardless of the type of incident or the number of casualties [24]. To summarize, the definitions of MCIs vary between countries but the content is similar. Medical needs exceed, at least temporarily, the response capacities in the affected area, mainly due to a large number of victims and/or severity of injuries. 


\section{Swedish MCI organization}

In Sweden, all emergency agencies, including the rescue service, police, and health care, have mutual responsibility for emergency and MCI management despite being governed by different legislations. The Swedish Civil Contingencies Agency (Myndigheten för Samhällsskydd och Beredskap, MSB) supports and coordinates civil emergency planning and crisis management together with local, regional and national authorities [105]. MSB has the responsibility to support and evaluate civil society's joint crisis management capability. Health care services and agencies need to evaluate and self-assess their own capability to manage MCIs by conducting exercises on a regular basis $[105,106]$.

In the Swedish medical response organization, regional and national duty officers (DO) available 24/7 act as gatekeepers of the health care services combined resources. Each county council has their own criteria for when to declare a situation a major incident, depending on the time of day, resources available, and the geographic setting. DOs also take into account the current situation at the receiving hospitals. The DO has the authority to instantly activate the regional preparedness plan at the appropriate level, and to act as initial commander over all regional health care resources. The DO normally alerts, receives, and shares information together with other agencies such as police, rescue services, and health care $[106,107]$.

In most European countries, physicians and nurses are part of the pre-hospital organization [108]. Although the education level of personnel is standardized in some cases, large differences do exist. There is an ongoing debate as to which combination of practitioners and their education level will yield the best results in pre-hospital care [109-111]. In Sweden, firemen usually arrive at the scene of an incident first and are able to access victims before paramedics and other medical staff. The rescue services arrive before the ambulance service in $64 \%$ of incidents according to incidents reports from 2004 to 2013 provided by MSB. According to the Swedish emergency response system, in the case of an $\mathrm{MCI}$, the first ambulance on scene is typically crewed by one emergency medical technician and one specialist registered nurse. The registered nurse will be appointed medical incident commander and will normally retain this position for the duration of the incident. If a physician arrives at the incident site, he or she focuses on acute medical assessment and acts as an advisor on medical decisions. The Rescue Services Incident Commander is responsible for rescue and safety [112]. 


\section{Trauma care and triage in low- and middle-income countries}

Every year more people die from traumatic injuries than from infections such as malaria, tuberculosis, and HIV/AIDS [113]. A certain number of lives could be saved every year in low- and middle-income countries if health care was improved to the level of high-income countries [114]. Beyond communicable and chronic diseases, the mortality caused by injuries in Africa is 116 per 100,000 population, compared with Europe with 49 per 100,000 population [115].

The use of epidemiologic analyses to assess the gains in prevention of injury has been advocated, reflecting the changing view of injuries as preventable events [116]. The burden of diseases and summary measures such as disabilityadjusted life years (DALYs) have been considered as useful indicators for health policy and planning purposes [117]. Globally, since 1990, there has been a remarkable declining trend in the rates of DALYs due to injury, but this decrease is largely present in high-income regions. There is a reverse trend in low- and middle-income countries such West and South sub-Saharan Africa. A reason for this trend may be the increase in motorization and traffic density, without comprehensive urban speed limit laws, seat belt laws and/or drink-drive laws, or poor enforcement if laws exist [116,118].

In Kenya, which is a low-income country in East Africa, the mortality caused by injuries is 101 per 100,000 population [115]. It is well known and described that injuries, particularly those sustained through road traffic accidents, are a major cause of death in the African region [113,115,119]. Statistics from the WHO reveal that, in 2015, 26.6 per 100,000 died in road traffic accidents in Africa. The corresponding numbers for Europe were 9.3 per 100,000 population [119]. Between 3000 and 13,000 people are killed annually on Kenyan roads, with an estimated road fatality rate of 29.1 per 100,000 population [119]. From a global perspective, injuries in general result in permanent disability among an economically productive young adult population [120].

One part in this thesis focuses on evaluating the possible benefit of in-hospital triage for trauma patients admitted to the ED at the Moi Teaching and Referral Hospital (MTRH) in Eldoret, Kenya (figure 6). MTRH is the second national referral hospital in Kenya after Kenyatta National Hospital in Nairobi. The hospital is located $310 \mathrm{~km}$ north west of Nairobi, Uasin Gishu County, in the North Rift region of Western Kenya. MTRH receives casualties from the whole western region of Kenya, parts of eastern Uganda, and the south part of 
Sudan with a catchment of over 16 million people. The bed capacity at the time of the study was 700 , of which six were intensive care unit beds.

Although receiving increased attention, implementing strategies to improve trauma care in developing countries to address the health burden on the emergency care service is still warranted [121]. Improved road safety legislation, reducing drunk driving $[119,122]$, development of pre-hospital care systems [123], and strengthened hospital trauma care have been suggested as interventions to mitigate this problem in the health care system [124].

The WHO defines an outcome measure as a "change in the health of an individual, group of people, or population that is attributed to an intervention or series of interventions" [125]. In the

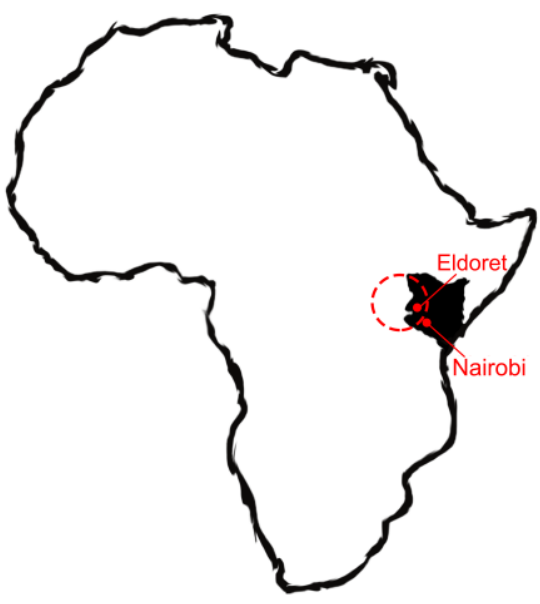

Figure 6. Geographic location of Eldoret, Kenya. The red dashed circle represents approximate catchment area of the MTRH hospital. health care system, performance indicators are used in order to determine standards and measure quality to improve patient management. Performance indicators are addressed and implemented in the field of disaster medicine $[63,126,127]$. Preventable death is a performance indicator, defined as the proportion of all deaths judged to have been preventable if optimal care had been given. Preventable death has become a standard tool when measuring and comparing the quality of trauma care and is essential in trauma research $[128,129]$.

Several scoring systems to assess injury severity with the aim of improving trauma care quality have been developed [130]. The Abbreviated Injury Scale (AIS) was the first comprehensive system [131]. Since then, other scoring systems use the AIS and other components in an attempt to describe an individual's overall injury severity. These systems includes the Injury Severity Score (ISS), which is commonly used [132], New Injury Severity Score (NISS), and Trauma and Injury Severity Score (TRISS). TRISS utilizes patient age, type of injury, RTS, and ISS to estimate the probability of survival. International Classification (ICD) codes are routinely collected in administrative databases. The ICD-based Injury Severity Score (ICISS) uses survival risk ratios (SRRs) to calculate the 
probability of survival for patients $[133,134]$. The Kampala Trauma Score (KTS) is a simplified combination of the RTS and ISS and evaluates injury primarily on the basis of physiologic, rather than anatomic, parameters. KTS has been validated for its ability to predict outcome in developing countries [135137].

Many hospitals in low-income countries lack a structured trauma system, including a formal triage system [138]. As an example, a study from Pakistan showed that $86 \%$ of pre-hospital personnel did not have a system for prioritizing patients and information to the hospital prior to arrival [139]. When a pre-hospital organization is limited or absent, patients are rarely prioritized and assessed, and treatment will not be performed until arrival at the hospital. Several hospitals in low-income countries have a large number of patients and the staff lack specific training, resulting in excessive waiting times before assessment of the patients. This may lead to deterioration of the injured patient's condition. A multicenter study from Tanzania showed that only $20 \%$ of the staff had proper training in triage [140].

\section{Scientific approach}

The science of disaster medicine is often observational or subjective, and much of the literature concerning disasters is based on reporting "lessons learned" [141]. It is demanding to evaluate the performance of the medical health care during a disaster. However, qualitative research by using performance indicators is available and can be used to determine standards and measure quality to improve patient management. Performance indicators are addressed and implemented in the field of disaster medicine $[63,126,127]$. However, a significant limitation in research studies in the disaster medicine area is related to the lack of standards for collecting and reporting data [1]. The research tools are not validated [142], or available to use or utilizable during a disaster [138].

Mass casualty research is not suitable for randomized, controlled, experimental studies because of the nature of the incidents. In an MCI, triage is an area that has been recognized as an essential part of patient management. Currently, a standardized methodology of triage is lacking, and this area is in need of a more evidence-based approach [143].

The perfect MCI triage system would be easy to learn, be adoptable, and accurately identify and categorize each casualty by severity and type of injury, to ensure that every casualty receives appropriate intervention and treatment. 
During a real incident, time and effort cannot be spent on education and training. In the meantime, we have to rely on the second best option, which is educational drills and exercises, as the basis for gaining new knowledge in the disaster medicine area [84].

The question arises whether exercises and training can be used to evaluate triage interventions, and thereby play a role in the development of a scientific analysis focusing on medical personnel performance in the pre-hospital setting. Furthermore, studies to evaluate if in-hospital triage systems can have an impact for the trauma patient are needed. 


\section{STUDY OBJECTIVES}

The research presented in this thesis aims to determine triage performance among pre-hospital personnel and investigate if there are any advantages with triage for the trauma patient. In this setting, the study objectives were to:

- Evaluate the triage component of globally used standardized trauma courses.

- Determine the ability of Swedish medical personnel who have attended the PHTLS course and physicians attending the ATLS course to perform triage for casualties in a simulated major incident using the mnemonic ABCDE.

- Investigate the benefit of a short educational intervention in triage skill training of rescue services personnel, and the retention of these triage skills six months later.

- Determine if an in-hospital triage system has the potential to improve management of trauma patients in an ED in a resource-poor setting. 


\section{MATERIAL AND METHODS}

A detailed description of the material and methods used can be reviewed in the respective papers, which are appended. A brief overview of the study design is presented below.

\section{Papers I and II}

Two multicenter cross-sectional studies were conducted. Data were collected from ATLS and PHTLS participants from different course sites in Sweden. The participants were evaluated with regard to triage skills using a triage skill questionnaire based on a previously validated instrument [144]. The triage questionnaire was handed out to the participants, together with an information letter, just before and after the course. The participant's assignment was to deal with three components of triage of victims in a simulated MCI: decision making; prioritization of 15 hypothetical casualties involved in a bus crash; and prioritization for evacuation. The time allowed to complete the triage skills questionnaire in both settings was 15 minutes, and the participants were asked to answer the questions in accordance with the ABCDE and SALT triage algorithms. In paper I, the results were analyzed using a paired test and ANOVA and Tukey post hoc tests. In paper II, significant differences between groups in the first and second section of the questionnaire were tested using Kruskal-Wallis tests coupled with Dunn's multiple comparisons tests. The results from the last section of the questionnaire were compared using chi-squared tests.

\section{Paper III}

This study was designed as a prospective randomized controlled trial. Eighty-six firemen were randomly assigned into two groups: one group used the ETS trauma cards, and the other group received an additional instructional lecture. Both groups received the same 30 minutes long lecture on how to perform triage according to the SALT algorithm. In the trauma card group, the participants were divided into subgroups and instructed to triage ten trauma victims according to the descriptions on the trauma cards. In the other group, written forms describing the same ten victims were used and discussed as a continuation of the lecture. Total training time was 60 minutes for both groups. A triage skill questionnaire, the same as used in papers I and II, was distributed before and after the educational intervention to measure individual triage skills. The questionnaire was applied again 6 months later. The groups' scores at baseline and after the intervention, as well as the post-test scores and the follow-up scores, were compared using the Wilcoxon signed rank test. The Mann-Whitney U test 
was used to investigate if previous experience of multi-casualty incidents, years in service, level of education, age, or educational model was related to improvement or retention. Due to the exploratory nature of the subgroup analyses, no correction for multiplicity was done.

\section{Paper IV}

The study was a prospective exploratory cohort study conducted on adult trauma patients admitted to the ED at MTRH, the second national referral hospital in Kenya. Trauma patient data included respiratory rate, pulse, blood pressure, $\mathrm{GCS}, \mathrm{SaO}_{2}$, body temperature, type and mechanism of injury. Descriptive data included time of accident and arrival at the ED, gender, age, and interventions performed at the ED. The patients were retrospectively categorized according to RETTS from patient records. Variables included in the analyses were ISS, waiting time before physician assessment, length of hospital stay, and mortality. The patient data were compared using non-parametric Kruskal-Wallis tests with Dunn's multiple comparisons post-tests.

\section{Ethical Considerations}

The regional ethics board was consulted regarding papers I, II, and III and agreed that the studies were not subject to ethical board regulation.

In paper IV, the research team included investigators from both Sweden and Kenya. Informed consent from the patients was not possible due to their medical condition and was not required according to the Institutional Research and Ethics Committee (IREC) and MTRH (FAN: IREC 1263). All data obtained in the study that could be traced to individual patients were removed before the final analysis and reporting. Patients involved in the study were taken care of within the present protocols and only monitored physical findings were registered. This study was registered in Clinicaltrials.gov (no. NCT02303613). 


\section{RESULTS}

A detailed description of all results obtained can be reviewed in the respective papers, which are appended. Some of the findings from the papers are summarized below.

\section{Papers I and II}

Two groups, ATLS participants (physicians) and PHTLS participants (prehospital personnel), were evaluated with regard to triage skills after completing the course. The ATLS group results were analyzed in paper I and compared with the PHTLS group in paper II. Neither ATLS nor PHTLS participants showed significant general improvement in their triage skills when tested. PHTLS participants with previous experience of MCI drills or real events significantly increased their score from pre-test to post-test (table 4).

Table 4. Section one in the questionnaire: decision making

\begin{tabular}{|c|c|c|c|c|c|c|}
\hline & $n$ & $\begin{array}{l}\text { Pre-test score } \\
\text { Mean } \pm \text { SD } \\
\end{array}$ & $\begin{array}{l}\text { Post-test score } \\
\text { Mean } \pm \text { SD }\end{array}$ & $\begin{array}{l}\text { Mean rank } \\
\text { difference }\end{array}$ & $\mathbf{P}$ & $H(d f)$ \\
\hline \multicolumn{7}{|l|}{ ATLS } \\
\hline whole group & 153 & $2.58 \pm 0.55$ & $2.65 \pm 0.55$ & -26.35 & 0.64 & $18.92(3)$ \\
\hline MCI experience & 62 & $2.5 \pm 0.59$ & $2.66 \pm 0.57$ & -49.44 & 0.37 & $23.05(3)$ \\
\hline \multicolumn{7}{|l|}{ PHTLS } \\
\hline whole group & 175 & $2.34 \pm 0.74$ & $2.57 \pm 0.61$ & -54.05 & 0.008 & $18.92(3)$ \\
\hline MCI experience & 130 & $2.4 \pm 0.68$ & $2.60 \pm 0.59$ & -51.77 & 0.04 & $23.05(3)$ \\
\hline
\end{tabular}

No significant improvements in triage skills of any of the groups were found in the second (table 5) or third sections of the questionnaire. 
Table 5. Section two in the questionnaire: points

\begin{tabular}{|c|c|c|c|c|c|c|}
\hline & $n$ & $\begin{array}{l}\text { Pre-test score } \\
\text { Mean } \pm \text { SD }\end{array}$ & $\begin{array}{l}\text { Post-test score } \\
\text { Mean } \pm \text { SD }\end{array}$ & $\begin{array}{l}\text { Mean rank } \\
\text { difference }\end{array}$ & $\mathbf{P}$ & $\mathbf{H}(\mathrm{df})$ \\
\hline \multicolumn{7}{|l|}{ ATLS } \\
\hline whole group & 153 & $9.46 \pm 1.48$ & $9.19 \pm 1.68$ & 23.12 & $>0.999$ & $3.22(3)$ \\
\hline MCI experience & 62 & $9.44 \pm 1.50$ & $9.26 \pm 1.70$ & 9.82 & $>0.999$ & $7.18(3)$ \\
\hline \multicolumn{7}{|l|}{ PHTLS } \\
\hline whole group & 174 & $9.51 \pm 1.78$ & $9.48 \pm 1.62$ & 1.22 & $>0.999$ & $3.22(3)$ \\
\hline MCI experience & 130 & $9.62 \pm 1.74$ & $9.56 \pm 1.54$ & 2.58 & $>0.999$ & $7.18(3)$ \\
\hline
\end{tabular}

\section{Paper III}

The results in paper III illustrate that the rescue services personnel significantly improved their triage skills, regardless of education group, and that this improvement was sustained 6 months later. The median pre-test score was 9 out of 15; the corresponding score for the post-test was 10 . This score was retained at the time of follow-up. Moreover, the accuracy in triage of the hypothetical patients was analyzed with regard to over and under triage. The rates of over triage were $23 \%$ before and $14 \%$ after the training session. At the time of followup, the rate of over triage had increased to $17 \%$. The rates of under triage were virtually unchanged at $18 \%$ and $17 \%$ before and after the training, respectively. Under triage rates decreased to $15 \%$ at the time of follow-up.

\section{Paper IV}

A total of 569 trauma patients presented at the ED at MTRH were included in the analyses. Most of the patients were male (85\%) and the mean age of all patients was 34 years. The average length of stay at the hospital was 12 days, with an average ISS of 12. Road traffic accident (RTA) was the most common incident type reported, accounting for $48.4 \%$ of admissions, followed by assault (31.4\%) (figure 7).

Figure 7. Chart depicting the frequency of incident types among the patients included in the study.

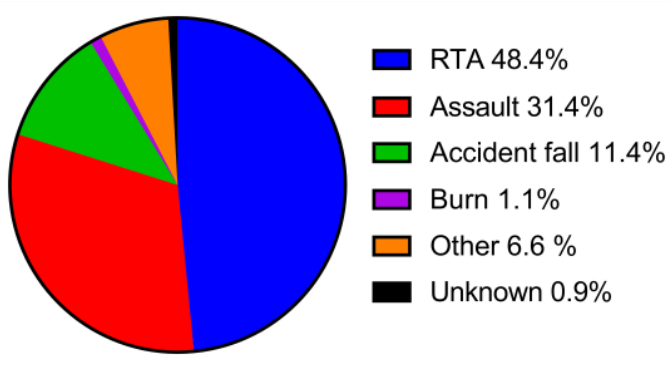


Almost $70 \%$ of the patients arrived at the ED by taxi, private car or police car; $17.6 \%$ of the patients were transported in an ambulance (figure 8).

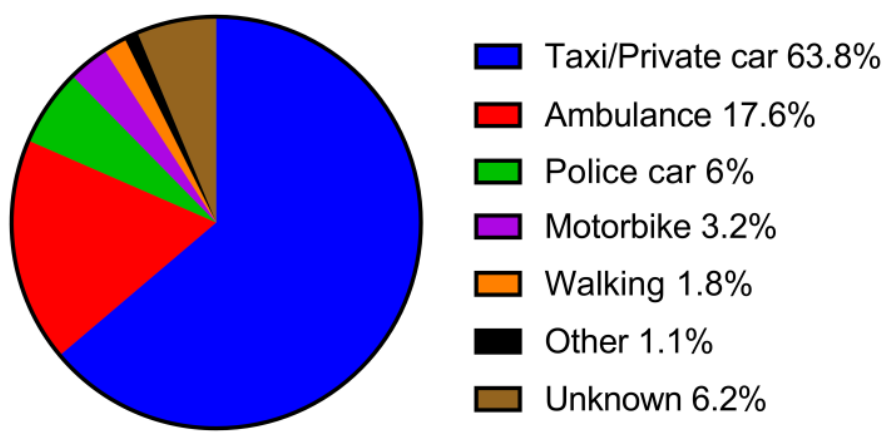

Figure 8. Chart depicting the frequency of modes of transportation to the hospital used by the patients included in the study.

The time period from admission to assessment by a physician was recorded for each patient, and the ISS was calculated for all patients. Retrospectively, all patients were color coded according to RETTS based on recorded vital parameters (table 6).

Table 6. Time to assessment and ISS for patients categorized according to RETTS

\begin{tabular}{lllll}
\hline $\begin{array}{l}\text { Color codes } \\
\text { According to } \\
\text { RETTS }\end{array}$ & $\begin{array}{l}\text { Time to assessment } \\
(\mathbf{m i n}) \\
\text { Mean } \pm \text { 95\% CI }\end{array}$ & $\begin{array}{l}\text { Maximum time to } \\
\text { assessment as } \\
\text { defined by RETTS }\end{array}$ & $\begin{array}{l}\text { ISS } \\
\text { Mean } \pm \text { SD }\end{array}$ & $n$ \\
\hline Red & $46(29-62)$ & immediate attention & $17 \pm 11$ & $77(14 \%)$ \\
Orange & $92(55-129)$ & within 20 min & $11 \pm 6$ & $83(15 \%)$ \\
Yellow & $79(52-106)$ & within 120 min & $12 \pm 7$ & $114(20 \%)$ \\
Green & $68(53-82)$ & not life threatening & $11 \pm 7$ & $295(51 \%)$ \\
Total & $71(60-82)$ & & $12 \pm 8$ & 569 \\
\hline
\end{tabular}


The retrospective categorization of patients according to the RETTS algorithm was compared with the ISS for each patient. This revealed a significantly higher average ISS in the red category compared with the other categories (figure 9). No significant differences with regard to ISS were observed when comparing the orange, yellow, and green categories.

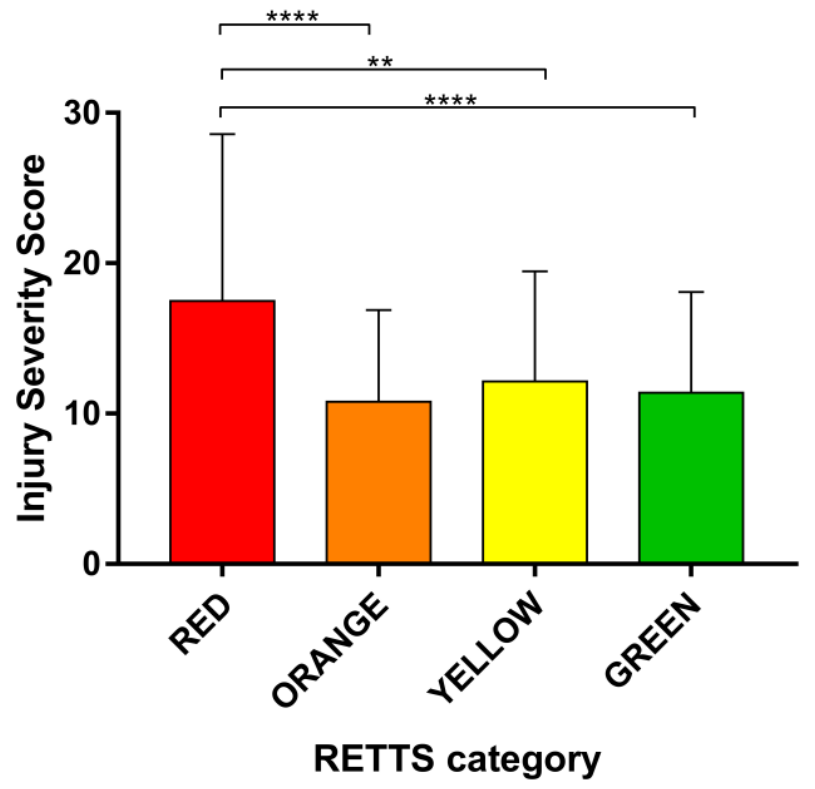

Figure 9. Graph illustrating the ISS of patients in relation to RETTS categories. $* * \mathrm{p}<0.01, * * * * \mathrm{p}<0.001$. 


\section{DISCUSSION}

The concept of triage has existed for centuries and is no less important today than it was during Napoleon's time. The problem remains the same - a number of casualties that overwhelms the health care system in a short period of time. In order to provide the greatest good to the greatest number of patients after a disaster or other major event, a simple system must be in place to prioritize treatment and management. This becomes even more apparent when time and resources are limited.

The perfect MCI triage system should ensure that every casualty receives the correct intervention and treatment, followed by accurate prioritization and transport to an appropriate definitive care facility. Moreover, the triage system should be easy to learn, simple to use, and be based on vital parameters. Vital parameters as part of the physiologic response to the injury function as a surrogate marker for the severity/acuity of the patient. Unfortunately, this ideal triage system has yet to be developed. Both trauma and triage are dynamic processes. The clinical condition of any given traumatically injured patient can change rapidly. External factors, such as resource availability, experience of the personnel involved, geographic locations, heavily influence triage decision-making.

As referred to earlier, a variety of triage methods are currently used, often without a strict consensus. Triage in the area of disaster management has been highlighted as a key factor in patient outcome. As a step toward comparing the accuracy of different triage systems, a consensus-based functional gold standard definition has been proposed [145]. No consensus regarding which patient should be classified to which category make it impossible to compare sensitivity, specificity, or accuracy between triage systems. A gold standard definition for each category was developed but without taking resources limitations into account [145]. However, this standard was indented to be used in quality improvement or research, not in clinical practice. There is evidence that systematic triage of MCI casualties is effective, but firm conclusions cannot be drawn in the absence of appropriate documentation [29]. Lessons learned from international emergency incidents illustrate that health care professionals do not feel sufficiently competent in the area in combination with unfamiliarity with the most common triage protocols $[59,146]$.

Moreover, there is a discrepancy between education/exercise and reality regarding practical application of triage skills $[27,147]$. For example, the widely 
taught use of triage tags has, to a large extent, not been used in real-life situations. Several reasons for not using triage tags have been identified, most relating to actual practical use [27].

A lot of effort has gone into creating effective triage teaching and training methods $[65,72,148,149]$. Courses such as ATLS and PHTLS have had an impact on trauma care education, and take place worldwide. The results presented in this thesis indicate that triage training does not necessarily increase the skills relevant to performing triage. Improving triage skills is not a specific objective for the ATLS and PHTLS courses. This was the case for the study presented in paper III, where the main focus of the education was triage. When comparing the outcome of the studies presented in papers I and II with the study in paper III, it is apparent that training should be specifically aimed at triage, and that the educational intervention can be of a relatively short duration. Moreover, under and over triage were evaluated in paper III, but not in papers I and II. Because this parameter has been shown to be an effective outcome measure to assess accurate triage, this would be interesting to study in the setting of papers I and II.

Evaluating training is essential for further improvement and development of the training itself, and to answer the question of whether the learning objectives have been reached. Learning is multidimensional and therefore requires multiple measures of different types of outcomes [73]. A good assessment method should be simple and flexible, but also based on theory [72]. One method of evaluation often used in triage training is to test learners before and after an intervention [84]. However, pre- and post-test designs must consider the priming effect of the material presented in a pre-test that might stimulate and/or improve memory of similar information in a post-test. Furthermore, the influence of other stimuli during the study period with no association with the education intervention, might affect changes in the learners' knowledge. Thus, it is difficult to evaluate if the improvement in knowledge is related to the training intervention or other competing influences [84]. So far, no conclusive evidence is present to determine the effectiveness of skills and knowledge in disaster management after training interventions [84].

Working in groups can be a particularly effective method of learning, particularly for professionals in a multidisciplinary environment [82]. It is also recognized that group activity can be extremely useful in assessing adults' ability to apply theoretical knowledge in practice [82]. During a group discussion in the ATLS course, triage is taught according to the mnemonic ABCDE, This is 
purely an anatomic triage, which has been shown to be inadequate to correctly assess the medical needs of patients. However, in the study presented in papers I and II, the participants were presented with physiologic parameters according to SALT, as well as information regarding the mechanisms of injury. Still, the ability to perform triage accurately did not improve significantly. Reasons for this lack of improvement may be poor course design, inadequate instruction, non-focused course objective, or unfamiliarity with the triage instruments provided. Further studies should focus on improving the triage training within the ATLS course, or providing separate triage-specific training for personnel potentially responding to an MCI.

Many considerations are important when aiming to deliver an effective training intervention to enhance performance in complex situations [150]. Training for difficult scenarios is about more than providing knowledge and skills to the learners. A broader view of training is needed. Therefore, educated instructors should be involved in the design and methods to be used in disaster education and training to enhance performance in complex and dynamic situations [150].

The distribution of victims and dilution of pre-hospital resources may affect the ability to perform accurate primary triage and make decisions regarding transport. Consequently, patients may or may be not be appropriately triaged when arriving at the ED. Initially after an incident, patients may also be arriving in private cars [151]. This is often the case when an MCI occurs in the vicinity of a hospital [152], but also when there is no pre-hospital organization. Medical personnel must have the knowledge and skills to be able to perform triage for all levels of care. The increased availability of resources, technical aids, and trained personnel at the hospital compared with the incident site, may have an impact on triage performance.

In Sweden, the predominant in-hospital triage system used is RETTS. According to RETTS, two variables are assessed: vital signs and chief complaints. After evaluation, a color-coded scale is applied to these two results. In paper IV, a retrospective classification of patients was performed according to RETTS. However, only the vital signs were used. For the information pertaining to the chief complaints to reach the ED, an alert patient, a person accompanying the injured to the ED, or a report from pre-hospital personnel is necessary. Knowledge of the mechanism of injury and the patient's medical condition is usually available in a well-structured emergency organization, as is the case in developed countries. In developing countries, where most trauma patients arrive 
at the ED in a taxi or private car, this information is not as obvious. The SATS has been designed with these circumstances in mind, and is suitable for use in resource-poor environments.

Because of the current absence of emergency medical training programs in Kenya, the implementation of a triage system is cumbersome. Moreover, the low numbers of EDs in the hospitals are generally staffed by clinical officers and recently graduated medical officers with minimal training in the care of acute, critical, or traumatic conditions. These EDs have no or very limited specialist coverage. In Kenya, triage is not taught as a specific subject, but is mentioned during emergency training. There is a need to improve emergency services in Kenya. Ultimately, residency-trained emergency providers should lead Kenyan referral centers and county hospital emergency services. This process, however, will take time. An intermediate solution is to train medical officers to better manage the initial triage and stabilization of patients with a wide variety of medical, surgical, and traumatic conditions at all times of day and night, and provide supervision and direction for Emergency Medical Services to be able coordinate disaster and emergency situations.

MOI University/MTRH, Kenya, has a long-standing relationship with Linköping University. Paper IV was conducted in collaboration between the International Medical Program, the universities, and the hospitals. This work may strengthen the long-term relationship and teamwork, which aim to build knowledge and educational exchange between the hospitals, and in the end, benefit the patients. This study also resulted in the creation of a trauma database containing ICD codes and specific patient parameters. This will enable future evaluation of interventions related to trauma care. 


\section{For the Future}

The science of disaster medicine is often observational or subjective and illustrated using a "lessons learned" terminology. Because knowledge derived from research on disaster medicine can have a tremendous influence on patients' health and subsequent treatment outcomes, an evidence-based assessment of the subject is essential in order for the field to move forward.

During an MCI, the focus is, and should be, to save as many victims as possible. Paperwork and documentation is of minor importance. But without reliable data or reports from MCIs, it is difficult to evaluate triage systems and their efficacy with the intention of continuous improvement. Therefore, it is time to change our mindset regarding documentation and collection of mass casualty triage data.

The challenge for the future is to implement a simple and effective triage system that is able to rapidly identify those who require lifesaving medical care, focus the response in order to use limited resources most effectively, and deliver the injured to hospitals where definitive care can be given. While efficient triage may be of great benefit, several other measures need to be taken in order to improve the care of traumatically injured patients, especially in developing countries. This includes preventive measures to minimize the occurrence and severity of traumatic injuries, establishing a well-functioning pre-hospital organization, and general improvement of the health care system as a whole.

As the complexity of the patient management and health care systems increases, triage, as during Napoleons time, will still be a vital tool in the first step of management for the trauma patient. 


\section{ACKNOWLEDGEMENTS}

I would like to express my profoundest gratitude to all of you who have supported me while I was working with my thesis. I would like to express my special thankfulness to:

My supervisor and friend Professor Tore Vikström, for the genuine and constant support you have given me throughout the years we have worked together and on this project. You and I have travelled all over the world together. This particular academic trip has been very special to me.

My co-supervisor and friend Carl-Oscar Jonsson for your scientific guidance in this, at times, emotional and challenging journey. For always being inspiring, and for supporting me, believing in me, and helping me to grow.

Dr Åke Björn and my friends Anna, Malin, Ann-Sofie, and Ruhija at the International Medical Program. You believed in me from the first moment and really supported me through this project.

Professor Simeon Mining, Dr John Tabu, Tecla, Nancy, Daisy, the research team, and all my colleagues and friends at MTRH, for your contribution to paper IV. Looking forward to future projects. I miss you all!

My friend Johan Junker, for constructive co-authorship in Papers II and IV. For your contribution with the design of all the figures, thorough reviewing, and genuine encouragement to finish this project. You were there when I needed it most.

Peter Berggren for your support with the statistics, additional perspectives and your positive way of coaching me.

All my friends and colleagues at KMC! Special appreciation to Danne Linghammar for the beautiful cover. You are my true and best friend, always there for me!

Marie Hindorf for all good talks, tears and laughter we have shared. Every day that passes by, moves you closer towards your goal.

My mother Lena and my father Ulf for your unconditional love! I know you are proud of me.

Finally, to my treasured and incredible husband Henry and our beloved children, Lovisa, Erika, and Johannes. Thank you all for your encouragement, patience, and endless boosting, especially when I needed it most. I love you all so much! 


\section{REFERENCES}

1 Debacker M, Hubloue I, Dhondt E, Rockenschaub G, Rüter A, Codreanu T, et al. Utstein-style template for uniform data reporting of acute medical response in disasters. PLoS Curr 2012;4:1-40.

2 Atiyeh B, Gunn S, William A, Dibo S. Primary triage of mass burn casualties with associated severe traumatic injuries. Ann Burns Fire Disasters 2013;26:48-52.

3 Frykberg ER. Triage: principles and practice. Scand J Surg 2005;94:272-8.

4 Iserson KV., Moskop JC. Triage in medicine, part I: concept, history, and types. Ann Emerg Med 2007;49:275-81.

$5 \quad$ Holt GR. Making difficult ethical decisions in patient care during natural disasters and other mass casualty events. Otolaryngol Head Neck Surg 2008;139:181-6.

6 Glassberg E, Lipsky AM, Abramovich A, Sergeev I, Hochman O, Ash N. A dynamic mass casualty incident at sea: lessons learned from the Mavi Marmara. $J$ Trauma Acute Care Surg 2013;75:292-7.

7 Centers for Disease Control and Prevention. Guidelines for field triage of injured patients. Recommendations of the National Expert Panel on field triage. Centres Dis Control Prev MMWR 2012;61:1-21.

8 Klein KR, Burkle Jr FM, Swienton R, King RV, Lehman T, North CS. Qualitative analysis of surveyed emergency responders and the identified factors that affect first stage of primary triage decision-making of mass casualty incidents. PLOS Curr 2016;8:Version 1.

9 Farrohknia N, Castrén M, Ehrenberg A, Lind L, Oredsson S, Jonsson H, et al. Emergency department triage scales and their components: a systematic review of the scientific evidence. Scand J Trauma Resusc Emerg Med 2011;19:42.

10 Gräff I, Goldschmidt B, Glien P, Bogdanow M, Fimmers R, Hoeft A, et al. The German version of the Manchester triage system and its quality criteria - first assessment of validity and reliability. PLoS One 2014;9:1-11.

11 Christ M, Grossmann F, Winter D, Bingisser R, Platz E. Modern triage in the emergency department. Dtsch Arztebl Int 2010;107:892-8.

12 Mirhaghi A, Mazlom R, Heydari A, Ebrahimi M. The reliability of the Manchester Triage System (MTS): a meta-analysis. J Evid Based Med 2016;1-12. 
13 Twomey M, Wallis LA, Myers JE. Limitations in validating emergency department triage scales. Emerg Med J 2007;24:477-9.

14 Mohan D, Rosengart MR, Farris C, Cohen E, Angus DC, Barnato AE, et al. Are the American College of Surgeons' guidelines for the transfer of trauma patients feasible? Arch Surg 2014;146:786-92.

15 Mohan D. Assessing the feasibility of the American College of Surgeons' benchmarks for the triage of trauma patients. Arch Surg 2011;146:786.

16 Newgard CD, Staudenmayer K, Hsia RY, Mann NC, Bulger EM, Holmes JF, et al. The cost of overtriage: more than one-third of low-risk injured patients were taken to major trauma centers. Health Aff 2013;32:1591-9.

17 Grossmann FF, Zumbrunn T, Frauchiger A, Delport K, Bingisser R, Nickel CH. At risk of undertriage? Testing the performance and accuracy of the emergency severity index in older emergency department patients. Ann Emerg Med 2012;60:317-25.

18 Rehn M, Eken T, Krüger AJ, Steen PA, Skaga NO, Lossius HM. Precision of field triage in patients brought to a trauma centre after introducing trauma team activation guidelines. Scand J Trauma Resusc Emerg Med 2009;17:1.

19 Barraco RD, Chiu WC, Bard MR, Dieter M, Iii TZH, Hoff WS. Practice management guidelines for the appropriate triage of the victim of trauma. 2010;1-34.

20 Ryan JM. Triage: principles and pressures. Eur J Trauma Emerg Surg 2008;34:427-32.

21 Koenig, Kristi L. Schultz C, editor. Disaster medicine: comprehensive principles and practise. Cambridge University Press; 2010.

22 Garner A, Lee A, Harrison K, Schultz CH M. Comparative analysis of multiplecasualty incident triage algorithms. Ann Emerg Med 2001;38:541-8.

23 Kilner T, Hall FJ. Triage decisions of United Kingdom police firearms officers using a multiple-casualty scenario paper exercise. Prehosp Disaster Med 2005;20:40-6.

24 Lennquist SE. Medical response to major incidents and disasters: Berlin: Springer; 2012.

25 Pelaccia T, Delplancq H, Triby E, Bartier JC, Leman C, Hadef H, et al. Can teaching methods based on pattern recognition skill development optimise triage in mass-casualty incidents? Emerg Med J 2009;26:899-902. 
26 Klein KR, Burkle Jr FM, Swienton R, King RV, Lehman T, North CS. Qualitative analysis of surveyed emergency responders and the identified factors that affect first stage of primary triage decision-making of mass casualty incidents. PLOS Curr 2016;8:Version 1.

27 Rådestad M, Lennquist Montán K, Rüter A, Castrén M, Svensson L, Gryth D, et al. Attitudes towards and experience of the use of triage tags in major incidents: a mixed method study. Prehosp Disaster Med 2016;31:376-85.

28 Sammut J, Cato DHT. Major Incident Medical Management and Support (MIMMS): a practical, multiple casualty, disaster-site training course for all Australian health care personnel. Emerg Med 2001;13:174-80.

29 Challen K, Walter D. Major incident triage: comparative validation using data from 7th July bombings. Injury 2013;44:629-33.

30 Alvarez BD, Razente DM, Lacerda DAM, Lother NS, Von-Bahten LC, Stahlschmidt CMM. Analysis of the Revised Trauma Score (RTS) in 200 victims of different trauma mechanisms. Rev Col Bras Cir 2016;43:334-40.

31 Mohyuddin GR, Alam Z, Malik UZ, Shakil O, Haq A. Revised trauma score as a predictor of outcome in trauma cases : experiences at a tertiary care hospital in Karachi, Pakistan. J Ayub Med Coll Abbottabad. 2015;27:584-6.

32 Mills AF. A simple yet effective decision support policy for mass-casualty triage. Eur J Oper Res 2016;253:734-45.

33 Jones N, White ML, Tofil N, Pickens M, Youngblood A, Zinkan L, et al. Randomized trial comparing two mass casualty triage systems (JumpSTART versus SALT) in a pediatric simulated mass casualty event. Prehosp Emerg Care 2014;18:41723.

34 Gebhart ME, Pence R. START triage: does it work? Disaster Manag Response 2007;5:68-73.

35 Kahn CA, Schultz CH, Miller KT, Anderson CL. Does START triage work? An outcomes assessment after a disaster. Ann Emerg Med 2009;54:424-30.e1.

36 Zoraster RM, Chidester C, Koenig W. Field triage and patient maldistribution in a mass-casualty incident. Prehosp Disaster Med 2007;22:224-9.

37 Bhalla MC, Frey J, Rider C, Nord M, Hegerhorst M. Simple Triage Algorithm and Rapid Treatment and Sort, Assess, Lifesaving, Interventions, Treatment, and Transportation mass casualty triage methods for sensitivity, specificity, and predictive values. Am J Emerg Med 2015;33:1687-91.

38 Lerner EB, Cone DC, Weinstein ES, Schwartz RB, Coule PL, Cronin M, et al. Mass casualty triage: an evaluation of the science and refinement of a national guideline. Disaster Med Public Health Prep 2011;5:129-37. 
39 Helsedirekoratet. Nasjonal veileder for masseskadetriage. 2013.

40 Bhalla MC, Frey J, Rider C, Nord M, Hegerhorst M. Simple Triage Algorithm and Rapid Treatment and Sort, Assess, Lifesaving, Interventions, Treatment, and Transportation mass casualty triage methods for sensitivity, specificity, and predictive values. Am J Emerg Med 2015;33:1687-91.

41 Lin GG, Scott JG. NIH Public Access 2012;100:130-4.

42 Jenkins JL, McCarthy ML, Sauer LM, Green GB, Stuart S, Thomas TL, et al. Mass-casualty triage: time for an evidence-based approach. Prehosp Disaster Med 2008;23:3-8.

43 Kilner TM, Brace SJ, Cooke MW, Stallard N, Bleetman A, Perkins GD. In 'big bang' major incidents do triage tools accurately predict clinical priority?: a systematic review of the literature. Injury 2011;42:460-8.

44 Price CL, Brace-McDonnell SJ, Stallard N, Bleetman A, Maconochie I, Perkins GD. Performance characteristics of five triage tools for major incidents involving traumatic injuries to children. Injury 2016;47:988-92.

45 Skyttberg N, Vicente J, Chen R, Blomqvist H, Koch S. How to improve vital sign data quality for use in clinical decision support systems? A qualitative study in nine Swedish emergency departments. BMC Med Inform Decis Mak 2016;16:61.

46 Farrokhnia N, Göransson KE. Swedish emergency department triage and interventions for improved patient flows: a national update. Scand J Trauma Resusc Emerg Med 2011;19:72.

47 Fernandes CMB, Tanabe P, Gilboy N, Johnson LA, McNair RS, Rosenau AM, et al. Five-level triage: a report from the ACEP/ENA five-level triage task force. $J$ Emerg Nurs 2005;31:39-50.

48 Grossmann FF, Delport K, Keller DI. Emergency Severity Index. Notfall Rettungsmedizin 2009;12:290-2.

49 Storm-Versloot MN, Vermeulen H, van Lammeren N, Luitse JSK, Goslings JC. Influence of the Manchester triage system on waiting time, treatment time, length of stay and patient satisfaction; a before and after study. Emerg Med J 2014;31:1318.

50 Widgren BR, Jourak M. Medical Emergency Triage and Treatment System (METTS): a new protocol in primary triage and secondary priority decision in emergency medicine. J Emerg Med 2011;40:623-8.

51 Rosedale K, Smith ZA, Davies H, Wood D. The effectiveness of the South African triage score (SATS) in a rural emergency department. South African Med J 2011;101:537-40. 
52 Gottschalk SB, Wood D, DeVries S, Wallis LA, Bruijns S. The Cape Triage Score: a new triage system South Africa. Proposal from the Cape Triage Group. Emerg Med J 2006;23:149-53.

53 Twomey M, De Sá A, Wallis LA, Myers JE. Inter-rater reliability of the South African Triage Scale: assessing two different cadres of health care workers in a real time environment. Afr J Emerg Med 2011;1:113-18.

54 Dalwai M, Tayler-Smith K. Implementation of a triage score system in an emergency room in Timergara, Pakistan. Public Health Action 2013;I:43-5.

55 Sunyoto T, Van den Bergh R, Valles P, Gutierrez R, Ayada L, Zachariah R, et al. Providing emergency care and assessing a patient triage system in a referral hospital in Somaliland: a cross-sectional study. BMC Health Serv Res 2014;14:531.

56 Ford JK, Schmidt AM. Emergency response training: strategies for enhancing realworld performance. J Hazard Mater 2000;75:195-215.

57 Debacker M, Van Utterbeeck F, Ullrich C, Dhondt E, Hubloue I. SIMEDIS: a discrete-event simulation model for testing responses to mass casualty incidents. $J$ Med Syst 2016;40:273.

58 Risavi BL, Terrell MA, Lee W, Holsten DL. Prehospital mass-casualty triage training - written versus moulage scenarios: how much do EMS providers retain? Prehosp Disaster Med 2013;28:251-6.

59 Pereira BM, Morales W, Cardoso RG, Fiorelli R, Fraga GP, Briggs SM. Lessons learned from a landslide catastrophe in Rio de Janeiro, Brazil. Am J Disaster Med $2013 ; 8: 253-8$.

60 Andreatta PB, Maslowski E, Petty S, Shim W, Marsh M, Hall T, et al. Virtual reality triage training provides a viable solution for disaster-preparedness. Acad Emerg Med 2010;17:870-6.

61 Nilsson H, Jonson CO, Vikström T, Bengtsson E, Thorfinn J, Huss F, et al. Simulation-assisted burn disaster planning. Burns 2013;39:1122-30.

62 Ingrassia PL, Ragazzoni L, Tengattini M, Carenzo L, Della Corte F. Nationwide program of education for undergraduates in the field of disaster medicine: development of a core curriculum centered on blended learning and simulation tools. Prehosp Disaster Med 2014;29:508-15.

63 Nilsson H. Demand for rapid and accurate regional medical response at major incidents. Dissertation, Linköping University. 2012.

64 Emergo Train System. http://www.emergotrain.com. Accessed Jan 7, 2017.

65 Lennquist S. Education and training in disaster medicine. Scand J Surg 2005;94:300-10. 
66 Badiali S, Giugni A, Marcis L. Testing the START triage protocol: can it improve the ability of nonmedical personnel to better triage patients during disasters and mass casualties incidents? Disaster Med Public Health Prep 2017; doi:10.1017/dmp.2016.151.

67 Luigi Ingrassia P, Ragazzoni L, Carenzo L, Colombo D, Ripoll Gallardo A, Della Corte F. Virtual reality and live simulation: a comparison between two simulation tools for assessing mass casualty triage skills. Eur J Emerg Med 2015;22:121-7.

68 Cohen D, Sevdalis N, Patel V, Taylor M, Lee H, Vokes M, et al. Tactical and operational response to major incidents: feasibility and reliability of skills assessment using novel virtual environments. Resuscitation 2013;84:992-8.

69 Cone DC, Serra J, Kurland L. Comparison of the SALT and Smart triage systems using a virtual reality simulator with paramedic students. Eur J Emerg Med 2011;18:314-21.

70 Kraiger KJ, Ford JK, Salas E. Application of Cognitive, Skill-Based, and Affective Theories of Learning Outcomes to New Methods of Training Evaluation. J Appl Psychol 1993;78:311-328.

71 Kraiger TK, Ford JK, Salas E. Creating, implementing, and managing effective training and development systems in organizations: state-of-the-art lessons for practice. New York: John Wiley; 2013.

72 Khorram-Manesh A, Lupesco O, Friedl T, Arnim G, Kaptan K, Djalali AR, et al. Education in disaster management: what do we offer and what do we need? proposing a new global program. Disaster Med Public Health Prep 2016;10:854-73.

73 Salas E, Tannenbaum SI, Kraiger K, Smith-Jentsch KA. The science of training and development in organizations: what matters in practice. Psychol Sci Public Interes 2012;13:74-101.

74 Sackett PR, Mullen EJ. Beyond formal experimental design: Towards an expanded view of the training evaluation process. Personnel Psychol 1989;46: doi:10.1111/j.1744-6570.1993.tb00887.x.

75 Amiel I, Simon D, Merin O, Ziv A. Mobile in situ simulation as a tool for evaluation and improvement of trauma treatment in the emergency department. J Surg Educ 2016;73:121-8.

76 Stenfors-Hayes T, Hult H, Dahlgren LO. What does it mean to be a good teacher and clinical supervisor in medical education? Adv Heal Sci Educ 2011;16:197210.

77 Kolb DA. Experiential learning: experience as the source of learning and development. Englewood Cliffs, NJ: Prentice Hall; 1988. 
78 Hawk TF, Shah AJ. Using learning style instruments to enhance student learning. J Innovative Educ 2007;5:1-19.

79 Kolb AY, Kolb DA. The Kolb learning style inventory — version 3.1. Technical Specifications. LSI Tech Man 2005:1-72

80 Medwid K, Smith S, Gang M. Use of in-situ simulation to investigate latent safety threats prior to opening a new emergency department. Saf Sci 2015;77:19-24.

81 Hägg-Martinell A, Hult H, Henriksson P, Kiessling A. Students perceive healthcare as a valuable learning environment when accepted as a part of the workplace community. Educ Health (Abingdon) 2014;27:15-23.

82 Advanced Life Support Group. Pocket guide to teaching for medical instructors. $2^{\text {nd }}$ ed. Manchester: Blackwell Publishing; 2008.

83 Roy MJ, Sticha DL, Kraus PL, Olsen DE. Simulation and virtual reality in medical education and therapy: a protocol. Cyberpsychol Behav 2006;9:245-7.

84 Williams J, Nocera M, Casteel C. The effectiveness of disaster training for health care workers: a systematic review. Ann Emerg Med 2008;52:7-9.

85 ATLS: European Meeting. Berlin; 2012.

86 Mohammad A, Branicki F, Abu-Zidan FM. Educational and clinical impact of advanced trauma life support (ATLS) courses: a systematic review. World J Surg 2014;38:322-9.

87 Thies K, Gwinnutt C, Driscoll P, Carneiro A, Gomes E, Araujo R, et al. The European Trauma Course--from concept to course. Resuscitation 2007;74:135-41.

88 Maeder MB, Germann S, Banz VM, Amsler F, Driscoll P, Zimmermann H EA. Swiss multidisciplinary and multilingual experience of the Advanced Trauma Life Support course: lessons for Europe. Eur J Emerg Med 2012;19:220-5.

89 Advanced Trauma Life Support: student course manual. 9th ed. Chicago: American College of Surgeons; 2012.

90 Sollid SJM, Rimstad R, Rehn M, Nakstad AR, Tomlinson A-E, Strand T, et al. Oslo government district bombing and Utøya island shooting July 22, 2011: The immediate prehospital emergency medical service response. Scand J Trauma Resusc Emerg Med 2012;20:3.

91 Wolf S, Partenheimer A, Voigt C, Kunze R, Adams HA, Lill H. Die Erstversorgungsklinik bei einem großschadensereignis MANV IV : Erfahrungen aus einer vollübung. Unfallchirurg 2009;112:565-74.

92 Salomone JP, editor. Prehospital trauma life support. 7th ed. Mosby Elsevier 2011. 
93 Pfeifer R, Teuben M, Andruszkow H, Barkatali BM, Pape HC. Mortality patterns in patients with multiple trauma: a systematic review of autopsy Studies. PLoS One 2016;11:1-9.

94 Spahn DR, Bouillon B, Cerny V, Coats TJ, Duranteau J, Fernández-Mondéjar E, et al. Management of bleeding and coagulopathy following major trauma: an updated European guideline. Crit Care 2013;17:1-45.

95 Loggers SAI, Koedam TWA, Giannakopoulos GF, Vandewalle E, Erwteman M, Zuidema WP. Definition of hemodynamic stability in blunt trauma patients: a systematic review and assessment amongst Dutch trauma team members. Eur $J$ Trauma Emerg Surg 2016:1-11.

96 Trunkey DD. Trauma. Accidental and intentional injuries account for more years of life lost in the U.S. than cancer and heart disease. Among the prescribed remedies are improved preventive efforts, speedier surgery and further research. Sci Am 1983;249:28-35.

97 Gomes E, Araújo R, Carneiro A, Dias C, Lecky FE, Costa-Pereira A. Mortality distribution in a trauma system: from data to health policy recommendations. Eur J Trauma Emerg Surg 2008;34:561-9.

98 Clark DE, Qian J, Sihler KC, Hallagan LD, Betensky RA. The distribution of survival times after injury. World J Surg 2012;36:1562-70.

99 Park JO, Shin S Do, Song KJ, Hong KJ, Kim J. Epidemiology of emergency medical services-assessed mass casualty incidents according to causes. $J$ Korean Med Sci 2016;31:449-56.

100 Schenk E, Wijetunge G, Mann NC, Lerner EB, Longthorne A, Dawson D. Epidemiology of mass casualty incidents in the United States. Prehosp Emerg Care 2014;18:408-16.

101 Goyet CDV De, Sarmiento JP, Grünewald F. Health response to the earthquake in Haiti: lessons to be learned for the next massive sudden onset disaster. Pan-American Health organization; 2010.

102 World Health Organization (WHO). Mass casualty management systems : strategies and guidelines for building health sector capacity. WHO; 2007.

103 Hardy SEJ. Major incident in Kent: a case report. Scand J Trauma Resusc Emerg Med 2015;23:1-6.

104 Adams P. Major incident procedures. Nursing (Lond). 1980;(14):623-5.

105 Swedish Civil Contingencies Agency (MSB). https://www.msb.se. Accessed Jan 7,2017 
106 The National Board of Health and Welfare. http://www.socialstyrelsen.se/. Accessed Jan 7, 2017.

107 Swedish Association of Local Authorities and Regions. https://skl.se. Accessed Jan 7, 2017.

108 Fevang E, Lockey D, Thompson J, Lossius HM, Collaboration TR. The top five research priorities in physician-provided pre-hospital critical care: a consensus report from a European research collaboration. Scand J Trauma Resusc Emerg Med 2011;19:1-8.

109 Kirves H, Handolin L, Niemelä M, Pitkäniemi J, Randell T. Paramedics' and prehospital physicians' assessments of anatomic injury in trauma patients: a cohort study. Scand J Trauma Resusc Emerg Med 2010;18:60.

110 Mulholland SA, Gabbe BJ, Cameron P. Is paramedic judgement useful in prehospital trauma triage? Injury 2005;36:1298-305.

111 Bøtker MT, Bakke SA, Christensen EF. A systematic review of controlled studies: do physicians increase survival with prehospital treatment? Scand J Trauma Resusc Emerg Med 2009;17:12.

112 Rådestad M. Evaluation of medical response in disaster preparedness. Thesis, Karolinska Institute; 2013.

113 Lozano R, Naghavi M, Foreman K, Lim S, Shibuya K, Aboyans V, et al. Global and regional mortality from 235 causes of death for 20 age groups in 1990 and 2010: a systematic analysis for the Global Burden of Disease Study 2010. Lancet 2012;380:2095-128.

114 Mock C, Joshipura M, Arreola-Risa C, Quansah R. An estimate of the number of lives that could be saved through improvements in trauma care globally. World $J$ Surg 2012;36:959-63.

115 World Health Organization (WHO). World health statistics. WHO; 2015.

116 Haagsma JA, Graetz N, Bolliger I, Naghavi M, Higashi H, Mullany EC, et al. The global burden of injury: incidence, mortality, disability-adjusted life years and time trends from the Global Burden of Disease study 2013. Inj Prev 2016;22:3-18.

117 Izadi N. The burden of road traffic injuries in Kermanshah Province, Iran, in 20102011: GBD 2010 method. Int J Inj Contr Saf Promot 2016.

118 Kassebaum NJ, Arora M, Barber RM, Bhutta ZA, Brown J, Carter A, et al. Global, regional, and national disability-adjusted life-years (DALYs) for 315 diseases and injuries and healthy life expectancy (HALE), 1990-2015: a systematic analysis for the Global Burden of Disease Study 2015. Lancet 2016;388:1603-58. 
119 World Health Organization (WHO). Global status report on road safety. WHO; 2015.

120 GBD 2015 Mortality and Causes of Death Collaborators. Global, regional, and national life expectancy, all-cause mortality, and cause-specific mortality for 249 causes of death, 1980-2015: a systematic analysis for the Global Burden of Disease Study 2015. Lancet 2016;388:1459-44.

121 Yeboah D, Mock C, Karikari P, Agyei-Baffour P, Donkor P, Ebel B. Minimizing preventable trauma deaths in a limited-resource setting: a test-case of a multidisciplinary panel review approach at the Komfo Anokye Teaching Hospital in Ghana. World J Surg 2014;38:1707-12.

122 Odhiambo FO, Beynon CM, Ogwang S, Hamel MJ, Howland O, Van Eijk AM, et al. Trauma-related mortality among adults in rural western Kenya: characterising deaths using data from a health and demographic surveillance system. PLoS One 2013;8:1-13.

123 Nielsen K, Mock C, Joshipura M, Rubiano AM, Zakariah A, Rivara F. Assessment of the Status of prehospital care in 13 low- and middle-income countries. Prehospital Emerg Care 2013;16:381-9.

124 Wesson HKH, Stevens KA, Bachani AM, Mogere S, Akungah D, Nyamari J, et al. Trauma systems in Kenya: a qualitative analysis at the district level. Qual Health Res 2015;25:589-99.

125 WHO. World Health Organization. http://www.who.int. Accessed Jan 31, 2017.

126 Nilsson H, Vikstrom T, Jonson CO. Performance indicators for initial regional medical response to major incidents: a possible quality control tool. Scand $J$ Trauma Resusc Emerg Med 2012;20:81.

127 Rådestad M, Nilsson H, Castrén M, Svensson L, Rüter A, Gryth D. Combining performance and outcome indicators can be used in a standardized way: a pilot study of two multidisciplinary, full-scale major aircraft exercises. Scand J Trauma Resusc Emerg Med 2012;20:58.

128 Schoeneberg C, Schilling M, Hussmann B, Schmitz D, Lendemans S, Ruchholtz S. Preventable and potentially preventable deaths in severely injured patients: a retrospective analysis including patterns of errors. Eur J Trauma Emerg Surg 2016; doi:10.1007/s00068-016-0670-9.

129 Oliver GJ, Walter DP. A Call for Consensus on methodology and terminology to improve comparability in the study of preventable prehospital trauma deaths: a systematic literature review. Acad Emerg Med 2016;23:503-10. 
130 Tohira H, Jacobs I, Mountain D, Gibson N, Yeo A. Systematic review of predictive performance of injury severity scoring tools. Scand J Trauma Resusc Emerg Med 2012;20:1-12.

131 Rating the severity of tissue damage. The abbreviated scale. JAMA 1971;:277-80.

132 Baker, S.P., O’Neill, B., Haddon Jr, W., Long W. The Injury Severity Score: a method for describing patients with multiple injuries and evaluation emergency care. J Trauma 1974; 14:187:187-96.

133 Gedeborg R, Chen L-H, Thiblin I, Byberg L, Melhus H, Michaelsson K, et al. Prehospital injury deaths--strengthening the case for prevention: nationwide cohort study. J Trauma Acute Care Surg 2012;72:765-72.

134 Bergeron E, Simons R, Linton C, Yang F, Tallon JM, Stewart TC, et al. Canadian benchmarks in trauma. J Trauma 2007;62:491-7.

135 Owor G, Kobusingye OC. Trauma registries as a tool for improved clinical assessment of trauma patients in an urban African hospital. East Cent African J Surg 2001;6:57-63.

136 Weeks SR, Stevens KA, Haider AH, Efron DT, Haut ER, Mackenzie EJ, et al. A modified Kampala trauma score (KTS) effectively predicts mortality in trauma patients. Injury 2016;47:125-9.

137 Kobusingye OC, Lett RR. Hospital-based trauma registries in Uganda. J Trauma 2000;48:498-502.

138 Aloyce R, Leshabari S, Brysiewicz P. Assessment of knowledge and skills of triage amongst nurses working in the emergency centres in Dar es Salaam, Tanzania. Afr J Emerg Med 2014;4:14-8.

139 Bhatti JA, Waseem H, Razzak JA, Shiekh N-U-L, Khoso AK, Salmi L-R. Availability and quality of prehospital care on Pakistani interurban roads. Ann Adv Automot Med 2013;57:257-64.

140 Baker T, Lugazia E, Eriksen J, Mwafongo V, Irestedt L, Konrad D. Emergency and critical care services in Tanzania: a survey of ten hospitals. BMC Health Serv Res 2013;13:140.

141 Auf Der Heide E. The importance of evidence-based disaster planning. Ann Emerg Med 2006;47:34-49.

142 Nekoie-Moghadam M, Kurland L, Moosazadeh M, Ingrassia PL, Della Corte F, Djalali A. Tools and checklists used for the evaluation of hospital disaster preparedness: a systematic review. Disaster Med Public Health Prep 2016;27:1-8. 
143 Legemaate GA, Burkle FM, Bierens JJLMLM. The evaluation of research methods during disaster exercises: applicability for improving disaster health management. Prehosp Disaster Med 2012;27:18-26.

144 Deluhery MR, Lerner EB, Pirrallo RG, Schwartz RB. Paramedic accuracy using SALT triage after a brief initial training. Prehosp Emerg Care 2011;15:526-32.

145 Lerner EB, Mckee CH, Cady CE, Cone DC, Colella MR, Cooper A, et al. A consensus-based gold standard for the evaluation of mass casualty triage systems. 2016;19:267-71.

146 Rosborough S. A tale of two responses: Haiti earthquake highlights the need for training in international disaster response. Disaster Med Public Health Prep 2010;4:21-3.

147 Postma ILE, Weel H, Heetveld MJ, Dan Der Zande I, Bijlsma TS, Bloemers FW, et al. Mass casualty triage after an airplane crash near Amsterdam. Injury 2013;44:1061-7.

148 Lee CWC, McLeod SL, Van Aarsen K, Klingel M, Franc JM, Peddle MB. First responder accuracy using SALT during mass-casualty incident simulation. Prehosp Disaster Med 2016;31:150-4.

149 Hansoti B, Kellogg DS, Aberle SJ, Broccoli MC, Feden J, French A, et al. Preparing emergency physicians for acute disaster response: a review of current training opportunities in the US. Prehosp Disaster Med 2016;31:643-47

150 Ford JK, Smith EM, Consulting A, Weissbein DA, Gully SM, Salas E. Relationships of goal orientation, metacognitive activity, and practice strategies with learning outcomes and transfer. J Appl Psychol 1998;83:218-33.

151 Strommen JJ, Waterman SM, Mitchell CA, Grogan BF. 2014 Fort Hood, Texas, mass casualty incident: reviews and perspectives. Curr Rev Musculoskelet Med 2015;8:298-303.

152 Nadworny D, Davis K, Miers C, Howrigan T, Broderick E, Boyd K, et al. Boston strong - one hospital's response to the 2013 Boston marathon bombings. J Emerg Nurs 2014;40:4:418-27. 


\section{Papers}

The articles associated with this thesis have been removed for copyright reasons. For more details about these see:

http://urn.kb.se/resolve?urn=urn:nbn:se:liu:diva-134595 